University of South Florida

DIGITAL COMMONS

Digital Commons @ University of

@ UNIVERSITY OF SOUTH FLORIDA

South Florida

March 2019

\title{
Water Scarcity in the Face of Hurricanes: Improving the Resilience of Potable Water Supplies in Selected Florida Counties
}

\author{
Fautemeh Sajadi Bami \\ University of South Florida, spider.lily.kibou@gmail.com
}

Follow this and additional works at: https://digitalcommons.usf.edu/etd

Part of the Environmental Sciences Commons

\section{Scholar Commons Citation}

Sajadi Bami, Fautemeh, "Water Scarcity in the Face of Hurricanes: Improving the Resilience of Potable Water Supplies in Selected Florida Counties" (2019). USF Tampa Graduate Theses and Dissertations. https://digitalcommons.usf.edu/etd/7923

This Thesis is brought to you for free and open access by the USF Graduate Theses and Dissertations at Digital Commons @ University of South Florida. It has been accepted for inclusion in USF Tampa Graduate Theses and Dissertations by an authorized administrator of Digital Commons @ University of South Florida. For more information, please contact digitalcommons@usf.edu. 
Water Scarcity in the Face of Hurricanes: Improving the Resilience of Potable Water Supplies in Selected Florida Counties

by

Fautemeh Sajadi Bami

A thesis submitted in partial fulfillment

of the requirements for the degree of

Master of Science Degree in Environmental Science and Policy

Department of Geosciences

College of Arts and Sciences

University of South Florida

Major Professor: Kamal Alsharif, Ph.D.

Connie Mizak, Ph.D.

Philip Van Beynen, Ph.D.

Date of Approval:

March 21, 2019

Keywords: Water quality, Hurricanes, Water management, Preparation, Emergency response, Drinking water

Copyright @ 2019, Fautemeh Sajadi Bami 


\section{ACKNOWLEDGMENTS}

I would like to thank my thesis advisor Dr. Alsharif for his advice and support these past two years. Dr. Alsharif always had time to discuss my thesis with me and to answer my queries about writing. Having a great advisor made the transition from undergraduate to graduate school much easier. His encouragement, motivation, and helpful feedback were greatly appreciated.

I would also like to thank Dr. Mizak. Her introduction of the Master's Environmental Science and Policy program inclined me to apply for the program and her kind support helped motivate me for this research. Furthermore, I would like to thank Dr. Van Beynen for his comments and support of my thesis research.

I would also like to thank the Fred L. and Helen M. Tharp Endowed Scholarship Fund from the University of South Florida for partially funding this research. 


\section{TABLE OF CONTENTS}

List of Tables ............................................................................................................ ii

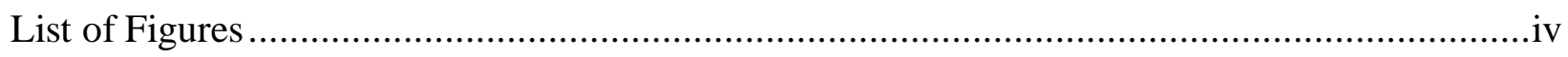

Abstract ………

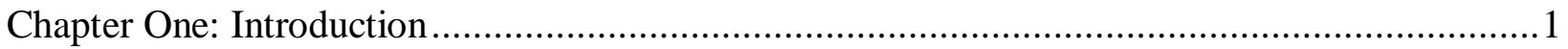

1.1 Purpose Statement and Argument ........................................................... 2

1.2 Background on the Problem at Hand ........................................................ 3

1.3 Background on Stakeholders ....................................................................

Chapter Two: Literature Review ................................................................................ 6

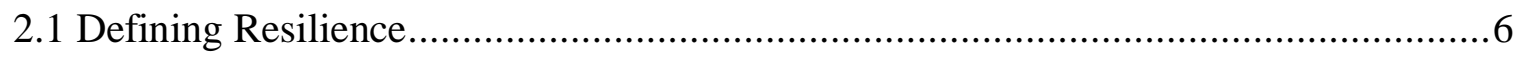

2.2 Review of Hurricane Issues, Preparations, and Responses .................................. 9

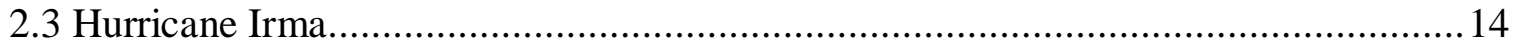

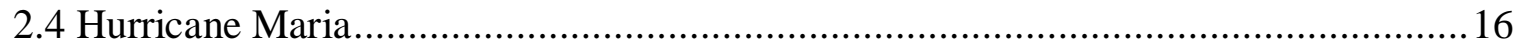

2.5 Department of Health by County...................................................................... 16

2.6 Potential Strategies in Dealing with Hurricanes.................................................26

2.6.1 Hurricane and Flood Mitigation Options...........................................26

2.6.2 Infrastructure resiliency measures................................................. 26

2.7 Improving on Current Preparations and Responses..........................................28

2.8 Revisiting the Argument and Answering the Call for Future Research ....................31

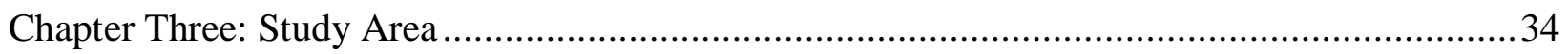

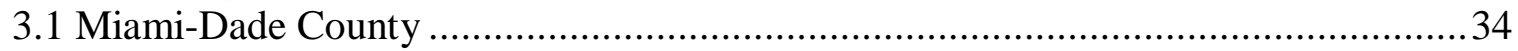

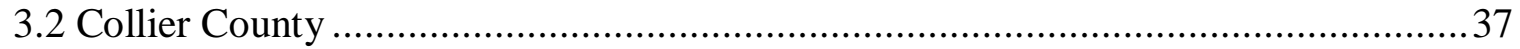

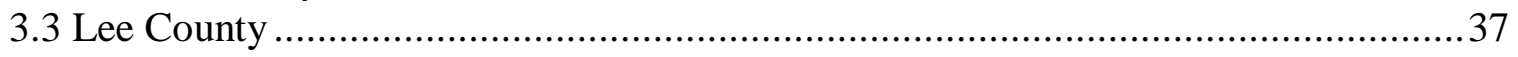

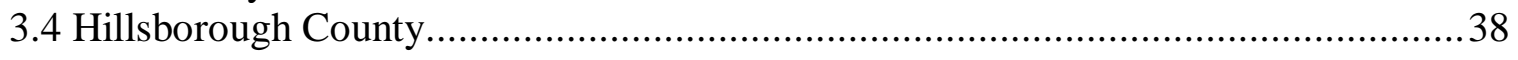

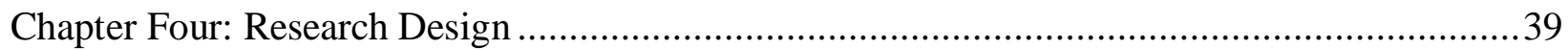

4.1 Research Question, Hypothesis, Problem Statement ........................................ 39

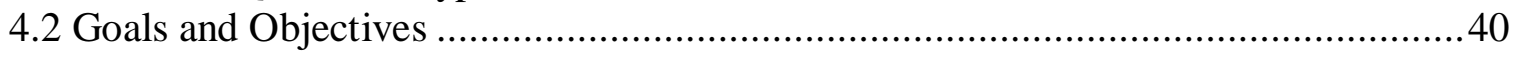

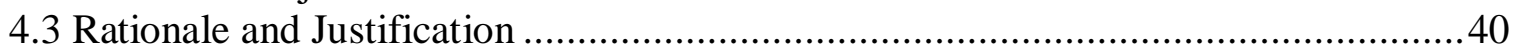

4.3.1 Intellectual Merit .................................................................. 40

4.3.2 Broader Impacts ................................................................ 41

Chapter Five: Methods ............................................................................................. 44

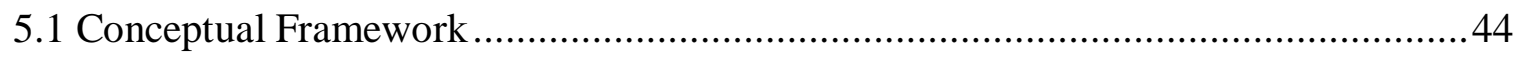

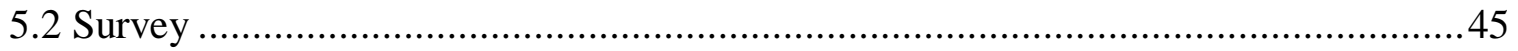




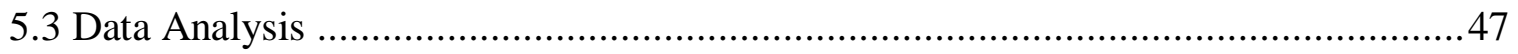

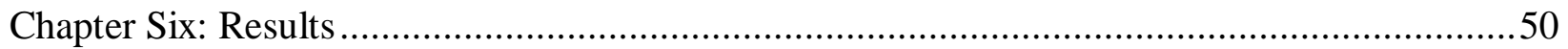

6.1 RQ1: To What Extent did People Experience Potable Water Shortages? ...................50

6.2 RQ2: How Long did These Shortages Last? ..........................................................50

6.3 RQ3: How Could These Shortages Have Been Avoided? .......................................55

6.4 RQ4: Do Management Practices Accomplish Their Own Goals Effectively? ...........58

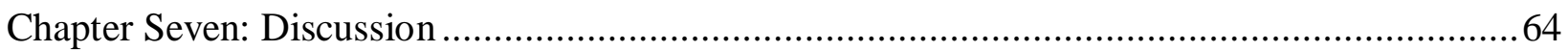

7.1 Examining RQ1 - Extent of Potable Water Shortages .............................................64

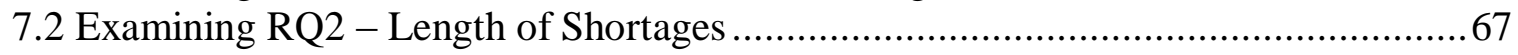

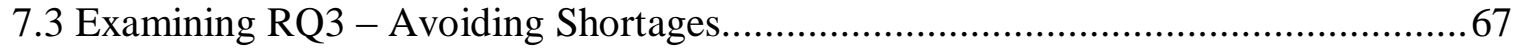

7.4 Examining RQ4 - Accomplishing Management Goals............................................70

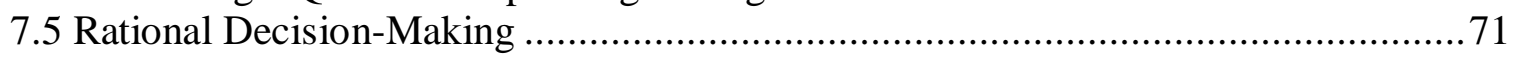

7.5.1 Step 1: Defining the Issue ...................................................................... 71

7.5.2 Step 2: Create Decision-Making Criteria …….......................................... 72

7.5.3 Step 3: Rank Criteria ......................................................................... 72

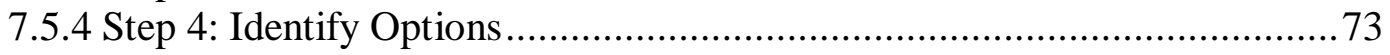

7.5.5 Step 5: Evaluate Options ........................................................................ 73

7.5.6 Step 6: Eliminate Poorer Options ............................................................... 75

7.5.7 Step 7: Choose Best Options (Recommendations for Improvement) ...........75

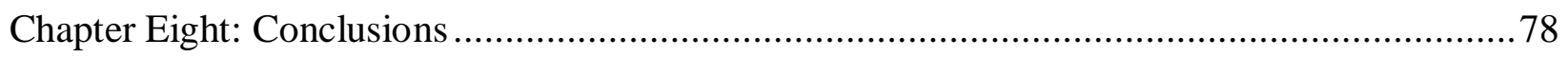

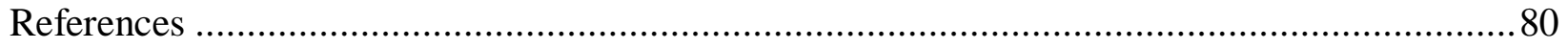

Appendix A: Water Scarcity in the Face of Hurricanes Questionnaire .....................................8 88

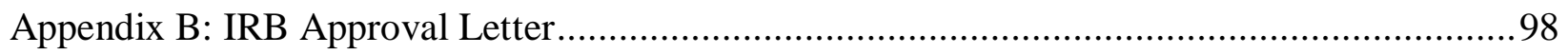

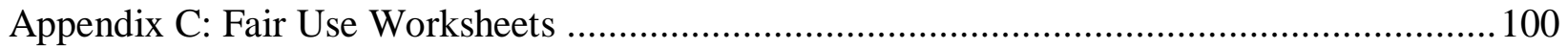




\section{LIST OF TABLES}

Table 1: Primary Responsibilities and Observations of the Department of Health in Each County for Hurricane Irma

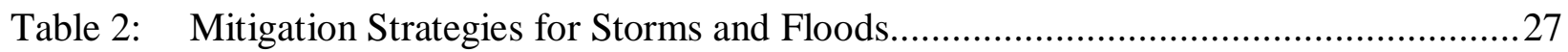

Table 3: Preparation and Response Efforts, Problems, Effects, and Improvements..................32

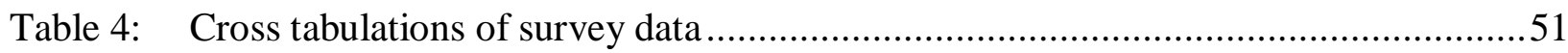

Table 5: Cross tabulations to explore relationships between age and other variables ..............52

Table 6: Cross tabulations of statistically significant relationships involving ethnicity ….......53

Table 7: Cross tabulations displaying people's perceived preparation adequacy and whether or not their preparations were actually sufficient during Hurricane Irma

Table 8: Cross tabulations showing statistically significant relationships between age, ethnicity, water treatment methods used, and information source for treatment methods

Table 9: Cross tabulations displaying statistically significant relationships between receiving emergency relief and whether or not respondents truly needed said relief 


\section{LIST OF FIGURES}

Figure 1: Results for a hurricane preparedness survey ........................................... 12

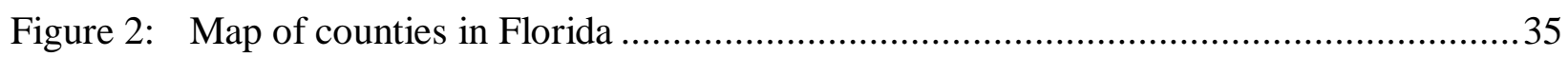

Figure 3: Map of language vulnerability of various counties in Florida ................................36

Figure 4: Map showing the socioeconomic vulnerability of various Florida counties..............36

Figure 5: Data for number of respondents and the time required to reacquire potable water ....55

Figure 6: Data for number of respondents and the time it took them to reacquire bottled

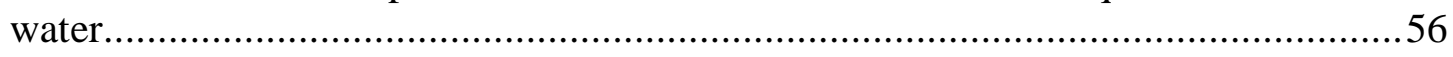

Figure 7: Data for number of respondents and the time required to reobtain municipal water ..57

Figure 8: Data for number of respondents and the time needed to reacquire potable water

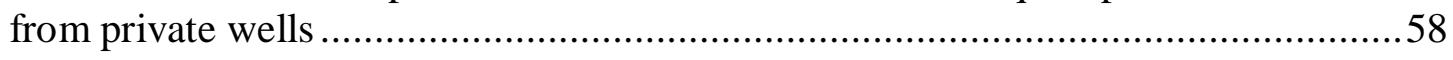

Figure 9: Data for respondents' satisfaction with aid by source .......................................6 63 


\begin{abstract}
Severe storms can threaten the reliability and accessibility of drinking water supplies. The state of Florida is frequently impacted by hurricanes and is often struck more than once a year. An example of this can be found in 2017 when hurricanes Harvey, Irma, and Maria caused much damage. Compromised utilities, well contamination, and shortages in bottled water and ice are just some of the problems that may threaten peoples' drinking water.

Faced with these issues, preparation and response efforts must be effective in order to promote human health. Recent events like Hurricane Irma caused shortages in potable water which suggest the need for improvements in these efforts. The purpose of this study was to review management policies (for both preparations and responses) in dealing with potable water paucity caused by Hurricane Irma. Current efforts for managing potable water supplies were researched across selected counties in Florida. The effectiveness and deficiencies of these policies were analyzed. A survey was utilized to gain an understanding of the effects of these policies from the people's perspective.
\end{abstract}

This study determined several issues with potable water management efforts in dealing with severe storms. These issues were: 1) Economic constraints preventing the obtainment of drinking water (particularly for the Hispanic ethnic group), 2) Lack of concern/care in keeping sanitary private well systems, 3) Policies to encourage locals to prepare to last three days without regular water supplies were inadequate since many people were left without water for far longer time periods, 4) Younger respondents experienced greater potable water shortages than the 
elderly, and 5) Many people who received emergency relief did not actually require aid. This study also identified potential improvements in both the short-term (emergency responses) and long-term (preparedness) management of drinking water in the face of hurricanes.

Recommendations were made to address each of the found issues and ameliorate the management of potable water. These recommendations were: 1) To promote enforcement of anti-price gouging laws 2) Enhancing education on the importance of a sanitary well system. 3) Enhancing infrastructure and power by increasing redundancy, storage capacity, structural integrity, backup power and structural stability; and/or promote education informing locals to prepare for water shortages that last longer than three days 4) Encouraging younger residents to be more involved with their community elders 5) Relief efforts should be made more effective in reaching their targeted populations (those in true need of aid). The results of this research may be used to enhance potable water management plans to avoid suffering and loss of wellbeing in future hurricanes. 


\section{CHAPTER ONE:}

\section{INTRODUCTION}

The state of Florida is well known for its beaches, humid weather, and abundant rains. To the general population, it is perhaps the last state that comes to mind when considering potable water scarcity. However, not all water meets drinking water standards and the risk of hurricanes and floods further threatens the reliability of drinking water supplies.

In the past, Florida has been struck by a multitude of hurricanes - often more than one per year. In 2004, four hurricanes (Charley, Frances, Ivan, and Jeanne) impacted Florida (Baker, 2011). Hurricane Ivan inflicted much property damage and resulted in twenty four lives lost (Bayleyegn, Wolkin, Oberst, Young, Sanchez, Phelps, Schulte, Rubin, \& Batts, 2006). Another example of a multi-hurricane year was found in 2005 with Hurricane Dennis and Hurricane Wilma (Baker, 2011). Hurricane Wilma had 175 miles per hour winds; over three million people lost electricity from this storm (Baker, 2011). More recently in 2017, three strong hurricanes (Harvey, Irma, and Maria) caused economic losses and deaths (Bostrom, Morss, Lazo, Demuth, \& Lazrus, 2018). These natural disasters can be powerful and highly destructive.

It is evident that the state of Florida is prone to hurricanes along with the negative impacts they bring. Among these impacts are power outages, loss of utilities, injuries, inland flooding, property damage, death, and difficulty in providing emergency relief (Baker, 2011; Bostrom et al., 2018). Shortages in bottled water and ice may occur as people prepare for the worst (Baker, 2011). The latter effect, in particular, makes household preparedness of vital 
importance to human health. Loss of electricity is another issue that can contribute to potable water shortages.

\subsection{Purpose Statement and Argument}

Recent natural disasters such as Hurricane Irma - where the strain on potable water supplies caused shortages — highlight the need for improved preparation and emergency response. The purpose of this study was to review management policies (for preparations and responses) in the event of drinking water shortages caused by Hurricane Irma in selected counties in Florida. Specifically, current plans for managing potable water supplies were analyzed across selected counties. The effects and deficiencies of these policies were then recognized. The end goal of this study was to identify and recommend potential improvements in both short-term (emergency responses) and long-term (preparedness) efforts addressing drinking water paucity.

This paper will argue that-while multiple preparations, responses, and mitigation strategies exist to counter the damage to potable water supplies caused by severe storms - there are gaps in said efforts that need to be adequately addressed. Robust preparations and response plans are necessary to avoid the suffering and loss in wellbeing associated with hurricanes.

To this end, relevant management and response efforts were evaluated—based on their prevalence during disaster scenarios - in order to assess their robustness in dealing with potable water paucity due to hurricanes and to identify deficiencies and potential improvements in

planning. A survey was created and distributed in Miami-Dade, Collier, Lee, and Hillsborough counties in order to gain an understanding of this issue from the local people's perspective. 


\subsection{Background on the Problem at Hand}

A disruption in drinking water availability after severe storms often results in illnesses. The heavy rains associated with hurricanes may cause flooding and sewer overflow (Khan, Deere, Leusch, Humpage, Jenkins, \& Cunliffe, 2015). In this way, torrential rains and flooding may cause public water supplies to become polluted (Florida Department of Health, 2017). These conditions result in a higher frequency of increased waterborne pathogen concentrations contaminating surface water (Khan et al., 2015). There is also the possibility of increased concentrations of viruses, bacteria, and trace metals (such as lead, iron, zinc, copper, and arsenic) — some of which imply contamination by sewage (Khan et al., 2015). This, in turn, can lead to people falling ill if they consume contaminated water. Worse yet, when a hurricane impacts a locality, the potable water supplies cannot be presumed safe (Florida Department of Health, 2017).

Hurricanes and their associated floods can also negatively impact important water infrastructure. These systems include wastewater and storm-water treatment, potable water treatment, and distribution (Matthews, 2015). These are dangerous threats to public safety and health and require sufficient preparation and reliable emergency response. Therefore, evaluating preparedness and responses to hurricanes is vital to improving resiliency to such hazards. In doing so, the health and wellbeing of Florida's citizens can be safeguarded.

\subsection{Background on Stakeholders}

There are multiple stakeholders that could be considered on this topic including: policymakers, weather-related or environmental organizations, businesses, developers of hurricaneprone communities, private health insurance companies, hospitals, public health departments, the 
general public, and the state of Florida itself. Authorities on the federal level work together with those on the state level to help people on the local level (FEMA, 2017). For example, federal actors such as the Federal Emergency Management Agency (FEMA) and the U.S. National Guard Bureau (NGB) coordinate with state emergency management agencies to perform a number of different emergency response activities (FEMA, 2017). These activities include:

1. Initial damage assessments to gain an understanding of the conditions on the ground.

2. Gathering intelligence to learn what is needed and assess the progress of operations.

3. Resource distribution of drinking water, meals, generators, cots, blankets, and other supplies.

4. Providing assistance and federal funding for locals.

FEMA and the Centers for Disease Control and Prevention (CDC) collaborate to disseminate information to the local populace regarding diseases and safety hazards. Hurricane survivors can also register for federal assistance via web or phone registration (FEMA, 2017).

While this wide range of stakeholders could be analyzed, this research was concerned with improving hurricane planning and response for the benefit of public health and human wellbeing. Therefore, for the purposes of this study, the local level (such as residents and homeowners) was the primary focus.

Key terms and concepts had to be defined with regard to how they were used in this study. This would promote better communication of research ideas, goals, and objectives. The key terms and concepts included: preparedness, emergency response, and resilience. The first two terms were clarified here. The last term, "resilience," required a deeper look into scholarly publications and would be clarified in the Literature Review section of this thesis. 
Preparedness in this study indicated the readiness to deal with shortages in drinking water whenever they may occur. In other words, it referred to the long-term management of potable water. On the other hand, this study viewed an emergency response as the reaction to sudden disturbances in potable water supply. Thus, it referred to the short-term management of potable water. 


\section{CHAPTER TWO:}

\section{LITERATURE REVIEW}

Since Hurricane Irma's occurrence — as of the date of this thesis - a large quantity of scholarly material pertaining to this subject has not yet been published. Therefore, effort was also directed in finding literature regarding hurricanes in general. Significant information found in journal articles that discussed other hurricanes was related back to Hurricane Irma. Besides peerreviewed journals, other sources were also perused for information regarding Hurricane Irma.

The concept of resilience plays an important role in this study. Scholarly material pertaining to this term was perused and the most significant articles found are discussed below. This information was then used to form a definition of "resilience" for this research.

Additionally, the Department of Health $(\mathrm{DOH})$ was contacted for every county in the study area (Hillsborough, Collier, Miami-Dade, Lee). Details regarding the DOH's responsibilities in dealing with Hurricane Irma were gathered through personal communications (including emails and telephone calls). This information was then tabulated for ease of review and evaluation.

\subsection{Defining Resilience}

Resilience is a term with significant implications to this research. However, its nebulous definition can lead to confusion and misinterpretation of results. Furthermore, the term may be treated differently among different authors. 
Resilience is often considered important in dealing with disturbances. According to Folke (2006), disturbance in resilient systems "has the potential to create opportunity for doing new things, for innovation and for development." On the other hand, "in vulnerable systems even small disturbances may cause dramatic social consequences" (Folke, 2006). The term "resilience" is found to be "increasingly influential..." (Wilkinson, 2011).

In the peer-reviewed literature on resilience, it was found that a proper definition has not been agreed upon (Torres \& Alsharif, 2017; Meerow, Newell, \& Stults, 2016; Cumming, 2011; Zhang \& Li, 2018; Sharifi \& Yamagata, 2014). Current definitions were described as "inconsistent and underdeveloped" (Meerow et al., 2016). The authors claimed that the Latin term "resilio" was a predecessor to the modern term "resilience." The definition is understood to mean "to bounce back" (Meerow et al., 2016). It was explained that the term resilience is conceptually vague, and that its definition has been flexible. This flexible terminology has allowed for people from different fields to cooperate with each other. However, it also means that the cooperators may not come to a precise definition (Meerow et al., 2016). It was further stated that "this vagueness can make resilience difficult to operationalize, or to develop generalizable indicators or metrics for" (Meerow et al., 2016). Resilience has been described as "'the capacity of social, economic and environmental systems to cope with a hazardous event or trend or disturbance, responding or reorganizing in ways that maintain their essential function, identity and structure, while also maintaining the capacity for adaptation, learning and transformation"” (Torres \& Alsharif, 2016; Torres, Alsharif, \& Tobin, 2018).

With regard to cities, resilience has been described as "the ability to absorb, adapt and respond to changes in an urban system" (Desouza \& Flanery, 2013). However, even in this sense, resilience is still considered to be a vague concept (Desouza \& Flanery, 2013). A 
multitude of dissimilar definitions may arise from different fields of study (Desouza \& Flanery, 2013).

Disasters such as hurricanes can cause sudden and severe disturbances. However, Carpenter, Walker, Anderies, and Abel (2001) indicated that "the best way to cope with surprise is resilience..." Resilience has been defined as "the magnitude of disturbance that can be tolerated before a socioecological system moves to a different region of state space controlled by a different set of processes" (Carpenter et al., 2001). There were different facets of meaning to the term "resilience." For example, it may be associated with the concept of sustainability, or it may be treated as a quantity for measure (Carpenter et al., 2001). The concept of resilience was frequently associated with the concept of sustainability. Another definition for resilience was: "the capacity of a system to undergo disturbance and maintain its functions and controls...measured by the magnitude of disturbance the system can tolerate and still persist" (Carpenter et al., 2001). However, resilience may also be measured by "the ability of the system to resist disturbance and the rate at which it returns to equilibrium following disturbance." (Carpenter et al., 2001).

It was clear that resilience can allow for the potential to draw positive outcomes from events of disturbance. However, with no set definition for this important term, it became imperative that it be defined to avoid confusion in this study. Therefore, for the purposes of this research, the term "resilience" will refer to: the ability of the system to promptly and effectively return to its original state after a disturbance.

Here, the "system" of interest consists of the selected study area (detailed later in this thesis). The "original state" refers to pre-disaster conditions when the system could better meet the potable water needs of its inhabitants. The return to the original state should be both: 
"prompt" so as to be relevant on a timescale significant to the people's wellbeing, and “effective" such that people's drinking water issues are addressed satisfactorily. The "disturbance" is anticipated from the severe storms and hurricanes that so frequent Florida.

For this study, resilience was measured by the speed and efficacy of preparations and emergency responses to Hurricane Irma. This was evaluated via a survey of people who lived through the storm.

A system with high resilience can promote its people's health and wellbeing more efficiently. On the other hand, a system with low resilience will not be able to adequately provide for its people. Thus, improving the system's resilience would lead to enhanced preparation and response to disasters and ultimately minimize human suffering.

\subsection{Review of Hurricane Issues, Preparations, and Responses}

Polices can directly or indirectly affect the degree of hurricane impacts. For example, building codes regulate the requirements for construction, and maintenance of buildings which then affects their susceptibility to hurricane damages. In the event of disasters, counties have their own policies for emergency management.

Hillsborough County disseminates emergency information through an official mass notification system called HCFL Alert and an emergency management webpage (Hillsborough County, 2018). With regard to hurricanes and potable water, residents are informed of current active storms, evacuation announcements, flooding information, and drainage issues. Residents are advised to prepare bottled water and purification tablets in case traditional drinking water supplies are compromised (Hillsborough County, 2018). It is encouraged that people make preparations to last for at least three days. 
The Collier County Emergency Management Division provides current information on floods, weather events, and disaster planning. They also suggest preparing for hurricanes by stocking purification tablets and one gallon of drinking water per person per day (Collier County, 2018). Residents are advised to be ready to last without traditional drinking water for three days at least.

Lee County's official website is very organized in its preparation and disaster information (Lee County Southwest Florida, 2018). Residents can learn about advance planning, flood hazards, and what supplies to stock. The county advises its people to prepare enough drinking water (one gallon per person per day) to last for seven days. Lee County's Department of Public Safety (also called Emergency Management or Lee County Emergency Operations Center) provides a preparation guide for a wide range of disasters including hurricanes. The guide is available in three different languages (English, Spanish, and Haitian Creole) (Lee County Southwest Florida, 2018).

Miami-Dade County provides a hurricane readiness guide which educates the public on hurricane preparation measures (Miami-Dade County, 2018). Residents are told to stock enough drinking water (one gallon per person per day) to last three to seven days. A color-coded map of storm surge zones is also provided to promote better planning (Miami-Dade County, 2018).

However, most of the policies for hurricane preparation and response efforts are predominantly concerned with sheltering and evacuations as opposed to concentrating on drinking water. With specific regard to hurricanes and potable water supplies, policies seem to be primarily focused on:

1. Advising the public on how to prepare for shortages and what necessities to stock. 
2. Informing locals of what actions to take should normal drinking water supplies be compromised.

3. Disseminating public safety announcements regarding the status of water supplies.

4. Providing relief when needed.

The heavy rains and floods from hurricanes have negative impacts on potable water quality which can last for weeks after water levels return to normal (Ruecker, Uzun, Karanfil, Tsui, \& Chow, 2017). In a discussion on excess precipitation and storm surges, it was mentioned that "flood events are a present and future cause of concern as observed from recent storms such as the 2016 Louisiana flood and Hurricanes Harvey, Irma, and Maria” (Bilskie \& Hagen, 2018).

Heavy flooding may result in sewage overflows and fecal contamination as seen with Hurricane Harvey (Kapoor, Gupta, Pasha, \& Phan, 2018). Flooding may cause heightened disease outbreaks, disruption in sanitation services, and greater mortality (Carroll \& Frakt, 2017). In another article on drinking water regulations during severe storms, it was found that "public water systems in large metropolitan areas have substantial portions of their customer base at risk for a waterborne outbreak during a flooding event" (Exum, Betanzo, Schwab, Chen, Guikema, \& Harvey, 2018).

Household perceptions of hurricane readiness were often found to be inaccurate. When asked, households generally perceived themselves as sufficiently prepared to last three or more days after a hurricane (Baker, 2011). However, post-Hurricane Wilma relief efforts were hampered due to some households which required relief supplies despite their previous claims of being prepared (Baker, 2011). 
In the event of a hurricane, people usually hoard survival supplies. When expecting hurricanes, shops and the public may prepare by keeping flashlights, radios, grills, and generators. They may also stockpile non-perishable food, batteries, water, and ice (Figure 1) (Baker, 2011). In a survey done by Baker (2011), more than $80 \%$ of respondents had filled their vehicles' tanks with gasoline for the hurricanes in 2004-2005. Few people prepared with generators as compared to other survival supplies. Water and ice preparedness was below $80 \%$.

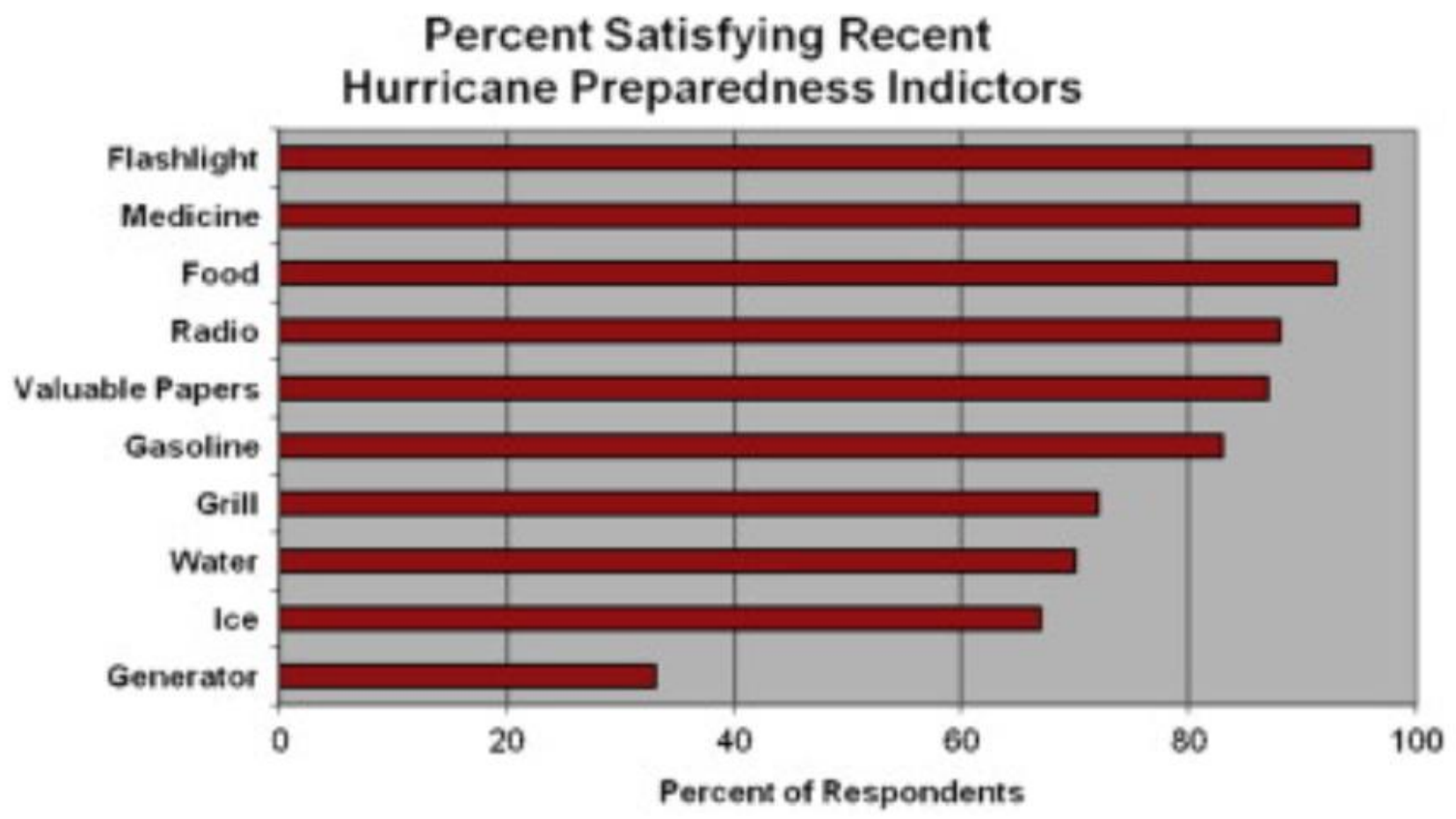

Figure 1: Results for a hurricane preparedness survey. Lowest preparedness was found to be in backup generators (Baker, 2011).

A fairly large proportion of people who were prepared for Hurricane Wilma were found to have also benefited from emergency relief (free ice, water, and food) (Baker, 2011). Out of all 
respondents to a survey done in Collier, Lee, and Miami-Dade Counties, 44\% stated that they were sufficiently prepared but took advantage of relief anyway (Baker, 2011). In fact, free relief supplies (including water, food, and ice) from the government had no significant effect on public wellbeing (Chatterjee \& Mozumder, 2015).

Additionally, the contaminated waters caused by hurricanes necessitate higher usage of chlorine for disinfection; and, this leads to higher levels of disinfection by-products in the treated water (Khan et al., 2015). Boil water advisories are issued depending on multiple factors such as high septic system density, insufficient maintenance, and increased rains (Khan et al., 2015). Both of these methods work in providing drinking water.

A study done on Hurricane Rita in Louisiana noted a lack of public knowledge in alternate drinking water sources (Ram, Blanton, Klinghoffer, Platek, Piper, Straif-Bourgeois, Bonner, \& Mintz, 2006). During this storm, electricity and gas was disrupted. However, residents were not aware that they could boil water for their potable water needs. Furthermore, they did not know enough about disinfection techniques (such as proper dosages per gallon) to alleviate their drinking water shortages (Ram et al., 2006). A lack of such survival knowledge among the public is a serious issue that should be avoided in any state, including Florida.

This lack of knowledge may not be surprising considering that modern information sources used to disseminate hurricane information (such as the internet) are considered serious distractors (Thatcher, Wretschko, \& Fridjhon, 2008). Internet applications such as social media are increasingly being used to disseminate hurricane information. Twitter, Facebook, and other services were utilized during Hurricane Irma to quickly distribute important updates and information. While some of these information sources offer a promising means of mass communication, they would be more beneficial if they were "... moderated by more trained 
emergency responders..." (MacMillan, 2017). Despite these information sources' uses, it is important to note that the internet's applications (including social functions and entertainment) are considered highly distracting from other more important applications (Thatcher, Wretschko, \& Fridjhon, 2008).

\subsection{Hurricane Irma}

Hurricane Irma was a category 5 hurricane that caused much panic for Florida residents (Shuckburgh, Mitchell, \& Stott, 2017). This severe storm was “...one of the strongest Atlantic hurricanes in history before landfall..." (Senkbeil, Collins, \& Reed, 2019). In fact, the ensuing evacuation was “...the largest evacuation in the history of the United States..." (Collins, Ersing, Polen, Saunders, \& Senkbeil, 2018). Response efforts were primarily concerned with shelters and evacuations (Florida Disaster Division of Emergency Management, 2018).

Price gouging for basic necessities (like bottled water) became a problem, and a hotline was set up to report such activity. Florida law bans excessive rises in the cost of necessities (such as food, gasoline, and drinking water) during emergencies (SunSentinel, 2017). Fines for such activities may exceed one thousand dollars and reach as high as twenty-five thousand dollars (SunSentinel, 2017). Thousands of complaints regarding price extortion were documented. Investigations were conducted to reach settlements - some of which reached twenty-five thousand dollars (SunSentinel, 2017). As of October 11, 2017 the number of price gouging complaints exceeded 14,000 in the state of Florida (TCPalm, 2017). Many of these affected the prices for drinking water. This was more than five times the number of reports recorded in the state in 2016 during Hurricane Matthew (TCPalm, 2017). Additional data on price gouging for drinking water during Hurricane Irma was obtained via electronic communications with the Director of the Office of Public Records at the Office of the Attorney General of Florida. For the 
four counties in the study area (Miami-Dade, Collier, Lee, and Hillsborough), there were 900 drinking water complaints due to price gouging. There were also 39 preliminary investigations and 6 enforcement cases (N. J. Weilhammer, personal communication, October 24, 2018).

There was concern that water treatment facilities may be damaged or otherwise rendered nonoperational (Florida Department of Health, 2017). In facilities that were still operational, hurricane-induced flooding may have polluted water supplies. In response to these dangers, public announcements were used to inform people of municipal water safety. Furthermore, wells were at risk of contamination during the flooding of properties. The Florida Department of Health Environmental Health and Engineering Division was responsible for testing wells that had been flooded (Florida Department of Health, 2017).

The Department of Health (DOH) advises against the use of potentially contaminated water for washing cutlery, preparing meals, making ice, and brushing teeth. Water that is safe for drinking and cooking includes bottled, treated, and boiled (for one minute to kill bacteria and parasites) water. Chlorine can be used to treat water (1/8 teaspoon or eight drops regular, unscented household bleach per gallon; mix thoroughly and leave for half an hour) (Florida Department of Health, 2017). The bleach should contain 4-6\% active ingredients, but may not kill parasites. Water treatment can also be accomplished via iodine or disinfection tablets. Bottled, treated, or boiled water should be used until regular water sources are tested and proven safe. Storage containers can be cleansed with bleach (one tablespoon per gallon) (Florida Department of Health, 2017). Wells and water treatment devices (excluding filters) may also be disinfected with bleach. The DOH listed steps in cleansing a polluted well. Chlorine is useful for killing microorganisms, however, it does not take care of chemical contaminants (Florida Department of Health, 2017). 
Supply shortages after hurricanes are particularly observable from the long lines that form at gas stations and grocery stores (Bostrom et al., 2018). Insufficient drinking water reserves and impaired transport — which can affect people's ability to access potable water-are especially significant (Bostrom et al., 2018).

\subsection{Hurricane Maria}

At its height, Hurricane Maria was also a category 5 hurricane (Fierro, Stevenson, \& Rabin, 2018). Many preparation and response policies for Hurricane Maria were focused on sheltering and evacuation. However, for Puerto Rico, this storm caused similar worries as those seen for Hurricane Irma. These concerns included: the risk to water treatment facilities, the combination of floods and failing infrastructure leading to contaminated water supplies, and supply shortages in basic necessities (including drinking water) (FEMA, 2017).

Hurricane Maria had destructive and ruinous effects in Puerto Rico (Garcia-Lopez, 2018). When Hurricane Maria swept through Puerto Rico, the island's infrastructure was devastated. The destruction of roads impeded travel and limited people's access to supplies such as potable water. The distribution systems (such as pipe networks) were damaged, thus compromising traditional water supplies. Electricity was lost which prevented pumping facilities from pumping water to its destinations (FEMA, 2017). There was also sewage overflow which raised the risk of drinking water supplies becoming contaminated. Recovery from Hurricane Maria was slow. This severe storm resulted in much human suffering.

\subsection{Department of Health by County}

Inquiries made at each county DOH cast light on their responsibilities during Hurricane Irma. The information was obtained through personal communications between the thesis author 
and county officials and was categorized based on activities prior to landfall (pre-hurricane), after landfall (post-hurricane), and overall priorities. Tabulation of the information enabled comparison of efforts between counties (Table 1).

Correspondence with the Environmental Specialist II (S. Witherspoon, personal communication, October 19, 2018) and the Environmental Supervisor II (T. LaDouceur, personal communication, January 23, 2019) in Hillsborough County yielded the following information for the Hillsborough County DOH. Preparation efforts involved the use of the Storm Tracker database (a statewide program activated for counties potentially impacted by the hurricane) to monitor large water systems (including wastewater systems) as to their operational status. Community water systems (CWSs) or Public Water Systems (PWSs) (systems that serve twentyfive persons or more) that provided water for more than three hundred and fifty people were obligated to form emergency response plans; 641 PWSs were regulated. The county DOH then reviewed these plans during inspections. Emails were sent to all water systems to give the emergency contact information of both the county DOH and the Hillsborough County emergency operations center. All water systems were also notified of the Storm Tracker database and were asked to update their operational status post crisis.

After the hurricane, well inspections were performed by the county DOH. It was concluded that massive flooding was not a major issue. However, electricity shortages affected water distribution and caused back flows which led to contamination. As a result, boil water advisories were issued. DOH inspectors were able to aid the Emergency Operations Center (EOC) by checking residences for electricity. DOH employees also worked in special needs shelters and asked people if they were in need of water. All PWSs were contacted via phone or email to check if they had electricity and to provide assistance where needed (such as issuing 
precautionary boil water notices or taking bacteriological samples). Staff ensured that the county DOH's laboratory had adequate capacity to test over a hundred water samples if needed. No PWSs were found to be contaminated, however, approximately eighty systems had lost electricity for at least a week. Some systems which had backup generators had exhausted their supply of fuel after three days.

The county DOH's overall priorities were to promote efficiency by ranking facilities. Those serving the highest number of people were ranked highest and were assisted first in obtaining resources necessary for proper operation. Emphasis was placed on PWSs since, according to the Environmental Supervisor II, "We do not regulate private wells or systems smaller than 25 persons" (T. LaDouceur, personal communication, January 23, 2019). A prioritization table was used to categorize tiers of priority to help guide response effort decisions. The DOH strove to ensure reliable and current emergency contact information that the PWSs could use. The DOH performed inspections by evaluating damages, provided assistance, and also ensured its lab had adequate capacity to test water samples.

Communications with the Director of Environmental Health \& Engineering in Collier County (R. Van Blaricom, personal communication, January 17, 2019) yielded the following information for the Collier County DOH. The DOH was primarily responsible for regulating PWSs or public wells. Preparation efforts were minimal and involved promoting education for how to deal with power shortages and flooding. It was noticed that many people were not too concerned over the water quality of their own wells because it was not a major source of their drinking water.

After landfall, county DOH workers were sent out to facilities to inspect equipment and collect water samples. In the case of private wells, the DOH assisted people with free water 
sampling for approximately ten days. Staff also disseminated educational information for disinfecting wells and how to take water samples. A satellite station was set up where people could pick up and drop off water sample kits. Approximately $67 \%$ of the water samples collected were contaminated (either total coliform bacteria or E. coli, or both) of about 1800-2000 water samples collected from residents. The county DOH gave out approximately 2500 sample kits, but only about $3 / 4$ were returned to be tested. A lack of regulation (no regular testing of water) resulted in the county DOH being uncertain of the number of wells that were contaminated due to the hurricane versus the number that were contaminated prior to the hurricane. Besides the issue of bacterial contamination, one person contacted the county DOH with concerns over pesticides in a private well (the person's neighbor's farm had been damaged and there was worry that its chemicals could affect the well). This case was referred to Tallahassee. It was observed that the hurricane caused people to take the quality of their well water more seriously and more conscientious of maintaining a sanitary system. Well owners became more attentive of well water quality (since they used it for washing food, brushing teeth, showering, and washing the dishes).

The overall priority of the Collier County DOH was to assist public wells although effort was also set aside for private wells. Such efforts consisted mostly of education, inspections, and free water testing.

Correspondence with the Environmental Specialist III in Miami-Dade County (R. Caballero, personal communication, January 24, 2019) provided the following information for the Miami-Dade County DOH. Preparation efforts for Hurricane Irma followed the standard procedure for tropical storms and hurricanes in South Florida:

a) Distribute Hurricane Preparedness letters to residents and PWSs 
b) Disseminate the Precautionary Boil Water Advisory

c) Request all PWSs and Limited Use Public Water Systems (LUs) to update their contact information

d) Activate Storm Tracker. Then, collect information from CWSs before and after the hurricane regarding fuel supply, need for state help, power outages, chemical reserves, emergency power, personnel on call, etc.

After landfall, the county DOH had two main observations. First, greater than $95 \%$ of the county were serviced by large water treatment plants which were adequately equipped to provide high quality water during the hurricane. No wells of these large plants were impacted. These residents were not impacted by the storm (excluding people relying on pumps to lift water and who did not prepare with backup power). Second, for small well systems, the main issue was power shortages which hindered pump function. No wells were contaminated. Response efforts concerning small systems included:

a) Updating the status of all PWSs by contacting (via email or cellphone) the operator or owner of the facility.

b) Inspections to evaluate damages.

c) Issue the Precautionary Boil Water Order

d) Collect bacteriological samples from distribution system(s) over two consecutive days. If the results were acceptable, and there was no damage to the system, the Precautionary Boil Water Order was lifted.

e) Quickly give the system a Sanitary Survey and then give recommendations to enhance the plant's function. 
The priorities of the county DOH were to ensure the distribution of information, update contact information with PWSs and LUs, and data collection. Later, after the hurricane, efforts were focused on data collection (update status of water systems), inspections, and safety (boil water orders, test distribution systems for contamination). Overall, this county DOH appeared highly organized.

Communications with the Executive Assistant I in Lee County (D. Kimberlin, personal communication, January 25,2019$)$ provided the following information for the Lee County DOH. The county DOH did not regulate private wells. Preparation efforts mainly went towards verifying the current contact information of CWSs. This was intended to allow CWSs to contact the DOH in case of issues caused by the hurricane which, in turn, would hasten post storm aid.

After landfall, the county DOH focused on contacting CWSs to ascertain their operational status. One system requested assistance for water sampling and bacterial analysis. None of the CWSs were found to have contaminated wells. The county DOH did offer free well testing for private wells, however, there was no regulation on the results of those tests. The county DOH stated that no other issues regarding drinking water were encountered.

The priorities of the Lee County DOH were to ensure reliable contact information and communication with CWSs. Overall, this county DOH was not as proactive as the other three had been. 
Table 1:

Primary Responsibilities and Observations of the Department of Health in Each County for Hurricane Irma

\begin{tabular}{|c|c|c|c|c|}
\hline $\begin{array}{c}\text { DOH in: } \rightarrow \\
\text { Info } \downarrow\end{array}$ & Hillsborough & Collier & Miami-Dade & Lee \\
\hline $\begin{array}{l}\text { Pre- } \\
\text { hurricane }\end{array}$ & $\begin{array}{l}\text { Storm Tracker used to } \\
\text { track status of water } \\
\text { systems } \\
\text { CWSs' emergency } \\
\text { response plans inspected } \\
\text { provide emergency contact } \\
\text { information to water } \\
\text { systems } \\
\text { Notified all water systems } \\
\text { about Storm Tracker and } \\
\text { asked them to update their } \\
\text { status post-storm }\end{array}$ & $\begin{array}{l}\text { Minimal preparation } \\
\text { Education on electrical } \\
\text { shortages and flooding } \\
\text { Many people not too } \\
\text { concerned for well water } \\
\text { quality }\end{array}$ & $\begin{array}{l}\text { Followed standard procedure for } \\
\text { hurricanes in South FL: } \\
\text { - Distributed Hurricane } \\
\text { Preparedness letter } \\
\text { - } \quad \text { Distributed Precautionary } \\
\text { Boil Water Advisory } \\
\text { - Updated contact } \\
\text { information for all PWSs } \\
\text { and LUs } \\
\text { - Activate Storm Tracker }\end{array}$ & $\begin{array}{l}\text { Updated contact } \\
\text { information for } \\
\text { CWSs }\end{array}$ \\
\hline $\begin{array}{l}\text { Post- } \\
\text { hurricane }\end{array}$ & $\begin{array}{l}\text { Well inspections } \\
\text { Massive flooding not an } \\
\text { issue } \\
\text { Power outages led to back } \\
\text { flows and contamination } \\
\text { Boil water advisories } \\
\text { isued }\end{array}$ & $\begin{array}{l}\text { Inspected equipment at } \\
\text { facilities and took water } \\
\text { samples } \\
\text { Free water sampling for } \\
\sim 10 \text { days, for private } \\
\text { wells } \\
\text { Disseminated education } \\
\text { and information about }\end{array}$ & $\begin{array}{l}>95 \% \text { of county received water } \\
\text { from plants equipped to provide } \\
\text { water during the hurricane. } \\
\text { No wells of the large plants were } \\
\text { affected. } \\
\text { For small well systems, main issue } \\
\text { was power outages hindering } \\
\text { pump function. No wells were } \\
\text { contaminated. }\end{array}$ & $\begin{array}{l}\text { Free water testing for } \\
\text { private wells (but no } \\
\text { regulation on the } \\
\text { results) } \\
\text { Contacted CWSs to } \\
\text { assess status } \\
\text { One utility requested } \\
\text { bacterial analysis }\end{array}$ \\
\hline
\end{tabular}




\section{Table 1 (continued)}

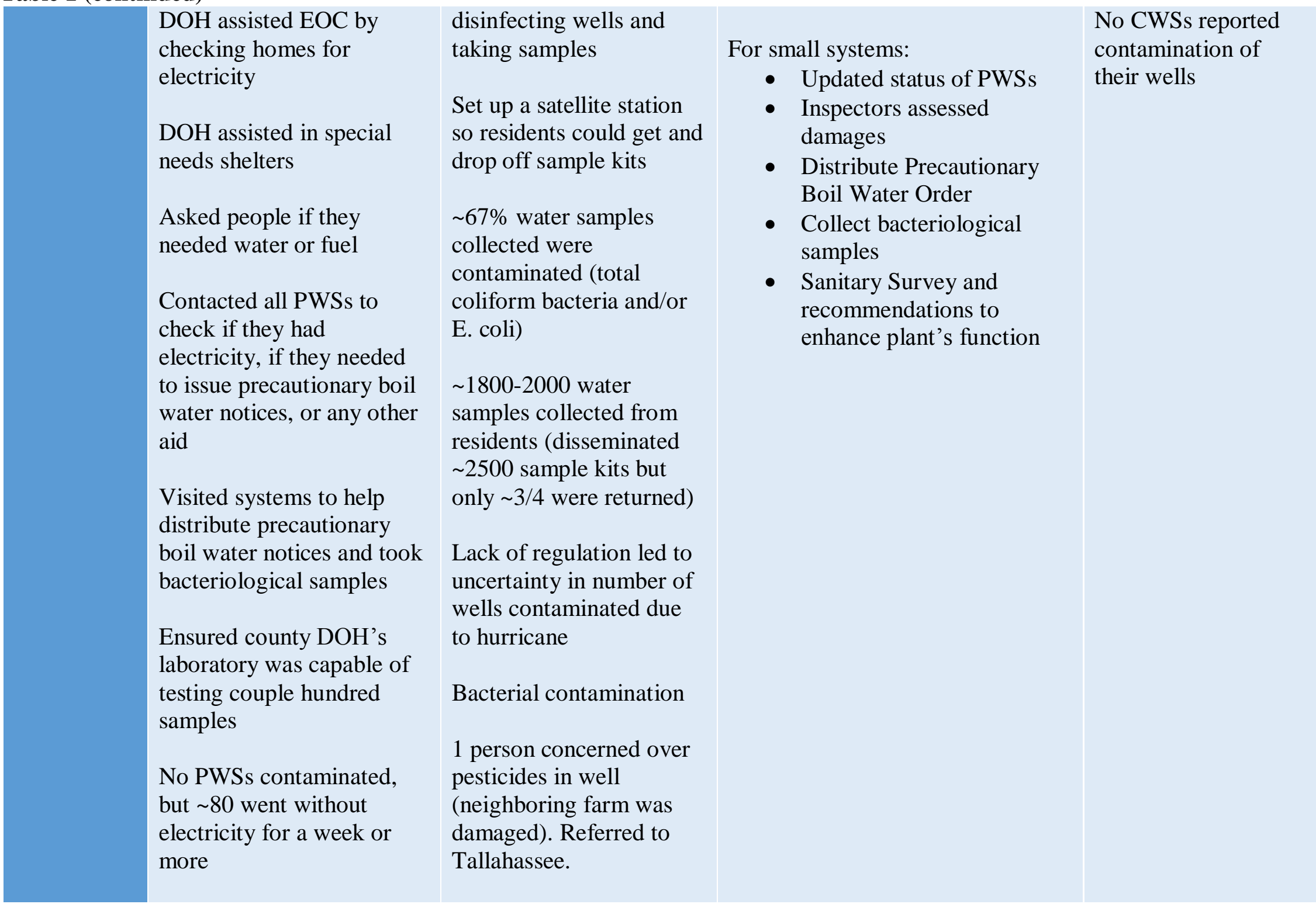


Table 1 (continued)

\begin{tabular}{|c|c|c|c|c|}
\hline & $\begin{array}{l}\text { After } 3 \text { days, some systems } \\
\text { with generators ran out of } \\
\text { fuel }\end{array}$ & $\begin{array}{l}\text { Hurricane caused owners } \\
\text { to think more about well } \\
\text { water quality and } \\
\text { maintaining a sanitary } \\
\text { system } \\
\text { Owners became more } \\
\text { diligent of well water } \\
\text { quality }\end{array}$ & & \\
\hline $\begin{array}{l}\text { Priorities } \\
\text { (focus of } \\
\text { efforts) }\end{array}$ & $\begin{array}{l}\text { Increased efficiency by } \\
\text { prioritizing facilities } \\
\text { serving highest number of } \\
\text { residents } \\
\text { Aid facilities to obtain } \\
\text { resources } \\
\text { Priority tiers table } \\
\text { prioritizes responses } \\
\text { Ensured reliable and up-to- } \\
\text { date emergency contact } \\
\text { information } \\
\text { Inspected and assisted } \\
\text { where needed } \\
\text { Ensured DOH's lab had } \\
\text { adequate capacity }\end{array}$ & $\begin{array}{l}\text { Public wells } \\
\text { Education } \\
\text { Inspections } \\
\text { Free water testing }\end{array}$ & $\begin{array}{l}\text { Highly organized and efficient } \\
\text { Distributing preparation } \\
\text { information } \\
\text { Updated contact information } \\
\text { Data collection } \\
\text { Updated operational status } \\
\text { Inspections } \\
\text { Boil water orders } \\
\text { Tested systems for contamination }\end{array}$ & $\begin{array}{l}\text { Ensuring reliable } \\
\text { contact information } \\
\text { and communication }\end{array}$ \\
\hline
\end{tabular}

Note: Information for this table was obtained through correspondence between the thesis author and: the Director of Environmental

Health \& Engineering in Collier County (R. Van Blaricom, personal communication, January 17, 2019); Environmental Specialist II 
(S. Witherspoon, personal communication, October 19, 2018) and the Environmental Supervisor II (T. LaDouceur, personal communication, January 23, 2019) in Hillsborough County; Environmental Specialist III in Miami-Dade County (R. Caballero, personal communication, January 24, 2019); and Executive Assistant I in Lee County (D. Kimberlin, personal communication, January 25, 2019). 


\subsection{Potential Strategies in Dealing with Hurricanes}

\subsubsection{Hurricane and Flood Mitigation Options}

A variety of mitigation strategies exist to alleviate the harmful impacts of hurricanes and floods (Table 2) (Khan et al., 2015). For example, diversified water sources would allow for alternative available supplies in case regular supplies were compromised. This applies to the alternate delivery strategy as well. Boil water advisories inform people of how to cleanse their water as does promoting disinfection processes. Each of the listed mitigation strategies is an effective option to counter hurricane impacts.

\subsubsection{Infrastructure resiliency measures}

Matthews (2015) discussed four aspects of resiliency necessary to ensure functioning water infrastructure during hurricanes. These aspects were:

1. Redundancy - This assures uninterrupted potable water service even if one pipeline is compromised. Having multiple supply facilities and a more extensive pipe capacity can help to offset water shortages caused by hurricanes.

2. Storage Capacity - This helps to avoid wastewater treatment plant (WWTP) overload. In turn, this also avoids overflow of wastewater. During overloads, WWTP operators usually discharge untreated wastewater into a water body. 


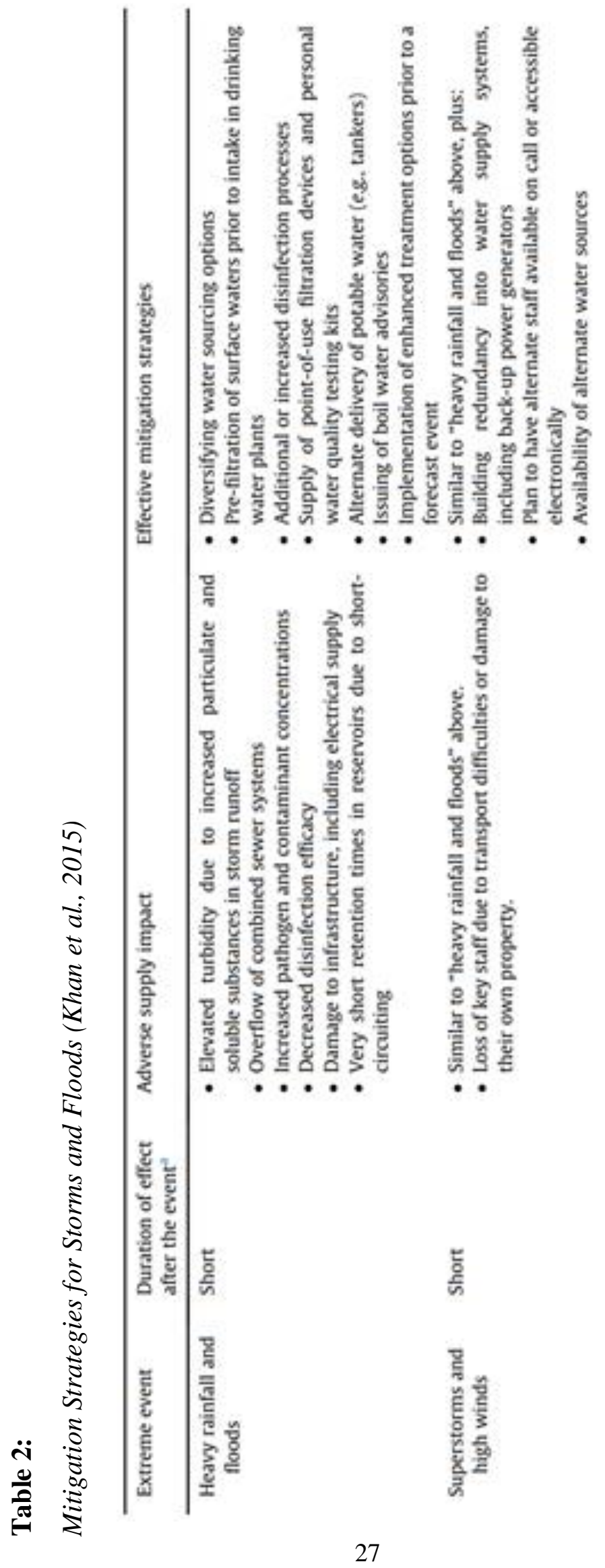


3. Structural Integrity - It is crucial that distribution and collection systems function properly and withstand storm impacts. Hurricane impacts involve greater pressure surges on the distribution system. Flood waters cause heightened external loads. Infiltrating water, from floods, leads to larger flows in collection infrastructure. This requires frequent evaluation of infrastructure. Faulty infrastructure should either be fixed or replaced.

4. Backup Power and Structural Stability - Backup power enables pumping facilities to continue to pump water to its destinations. Structural stability ensures resilience of physical structures during hurricanes.

Maintaining high standards in each of these four aspects would improve the resilience of the state to hurricane impacts. A high resilience will allow for a faster recovery from storm damages (Matthews, 2015).

\subsection{Improving on Current Preparations and Responses}

Hurricanes may be unavoidable, but the damage they bring does not have to be. Planning robust preparations and response efforts can mitigate much of the storms' negative impacts. This, in turn, can help Florida residents to maintain their wellbeing by keeping safe and healthy in the

future. Strategies with room for improvement were tabulated (Table 3) to summarize this thesis's literature findings and to clarify means to improve deficiencies.

Investing in the aforementioned potential improvements would greatly help to protect the state and its people from sudden drinking water shortages due to hurricanes. Taking proactive measures can increase the resilience of water supply and water quality (Khan et al., 2015). For example, preparing generators as a backup power source can aid in continued treatment and 
supply of potable water (Khan et al., 2015). Making various disinfection methods widespread can help to avoid waterborne disease outbreaks. The impacts of the chemical by-products from disinfection should also be monitored (Khan et al., 2015).

Given that hurricanes impede public utilities such as electricity and water (which depends on electricity to a degree), backup generators can play an important role in averting post-disaster hardships (Chatterjee \& Mozumder, 2015). Offering incentives (such as subsidies) to buy backup generators would be a good policy to make this mitigation strategy more widespread. One thing to consider is that, even if gas stations have fuel, they cannot operate without electricity (Chatterjee \& Mozumder, 2015). This can be a potential complication for those depending on gas-powered generators. The quick recovery of public utilities should be a high priority.

It is known that disrupted water supplies harm public health. Preparing adequate stocks of water and ice helps to protect human health in the event of a hurricane. However, government relief did not significantly affect public health (Chatterjee \& Mozumder, 2015). This may have been due to people taking advantage of free relief supplies even though they did not necessarily need them. This indicates a problem for emergency response efforts: even an adequate amount of relief delivered in a timely manner may be rendered insufficient. If emergency supplies are distributed to a large proportion of people who do not actually require them, then there may not be enough left for those who are in genuine need. This constraint on efficiency indicates that relief programs have room for improvement. Relief program efforts need to be more efficient in reaching their targeted populations (those in desperate need of help).

Enhanced public health education would help in alleviating hurricane impacts. An example of this would be early and fast dissemination of information regarding family disaster planning (Bayleyegn et al., 2006). Another example would involve raising awareness on 
alternate drinking water sources (Ram et al., 2006). This can include educating the public on emergency disinfection techniques and on the appropriate dosages per gallon.

Another issue is that public education is usually hindered after the storm (regular communication methods such as internet, radio, or television may be nonfunctional). Different means of communication (including community forums and displaying announcements at gas stations) could be beneficial. When regular communication methods become operational once more, daily broadcasts at set schedules and channels can be tracked by the public. Mobile clinics along with planning interim (short-term) shelters may also be useful to improve preparations and responses to hurricanes (Bayleyegn et al., 2006).

In Hurricane Maria, there is a lesson for Florida. The state and its residents should not settle with unreliable infrastructure. Florida's infrastructure is better than that of pre-hurricane Puerto Rico. However, if there is room for improvement, then improvements should be made. Proper preparations and infrastructure resiliency are crucial to avoid disasters as shown by Puerto Rico.

Redundancy, storage capacity, structural integrity, and structural stability are necessary to ensure water treatment facilities that can withstand the impacts of hurricanes. The resilience of the infrastructure is improved when: multiple water lines and facilities are available that can backup each other, WWTPs have the capacity to prevent wastewater overflow, facilities are able to maintain proper function during and after storms, and the facilities are physically strong enough to endure those storms. Diversifying water supplies and implementing alternative delivery methods (such as tankers) can help provide the public with drinking water. In the event of water contamination, chlorine disinfection is a viable solution. However, consideration must be given to the potential health impacts of the by-products left in the treated water. 
Price gouging presents another opportunity for improvement. Speaking in general about price gouging, Bae (2009) concluded that: "In an extreme case like a water shortage, even the maximum criminal penalty... will not prevent sellers from attempting to extract excessive prices of goods even at the cost of denying people of items essential for survival" (p.100). Promoting community vigilance and reporting via hotlines can help to deter price gouging activities.

Additionally, prosecuting violators can be made more effective by promoting enforcement of laws and educating consumers to record violations (Bae, 2009).

\subsection{Revisiting the Argument and Answering the Call for Future Research}

It is clear that there are many existing strategies to deal with hurricane-induced potable water scarcity. Adding to and improving on these is significant for promoting human health in face of severe storms. It is important to think proactively and ensure that a wide range of potable water options are available to the public.

Reviewing the scholarly literature revealed the need for future research in this field. For example, Baker (2011) measured household preparedness in Florida and concluded that future research should explore such variables as "perceived risk... and previous disaster experience, none of which were addressed in the present study." These factors have been considered in the survey distributed for this study.

Upon examining the effects of power and water supply disruptions, Chatterjee and Mozumder (2015) expressed the need for future studies to look into the effectiveness of relief efforts in helping their target populations. The thesis research accomplished this by gauging the degree to which potable water relief supplies reached its intended (those in dire need). 
Table 3:

Preparation and Response Efforts, Problems, Effects, and Improvements

\begin{tabular}{|c|c|c|c|}
\hline \multirow{2}{*}{$\begin{array}{l}\text { Preps / Response efforts } \\
\text { People hoard survival } \\
\text { supplies }\end{array}$} & Problem(s) & What happened & What can be done \\
\hline & $\begin{array}{l}\text { Household } \\
\text { perceptions of } \\
\text { readiness often } \\
\text { inaccurate }\end{array}$ & $\begin{array}{l}\text { Post-Hurricane Wilma } \\
\text { relief efforts hampered } \\
\text { due to households } \\
\text { which required relief } \\
\text { despite previous claims } \\
\text { of being prepared } \\
\text { Free relief supplies } \\
\text { from the government } \\
\text { had no significant } \\
\text { effect on public } \\
\text { wellbeing }\end{array}$ & $\begin{array}{l}\text { Relief program efforts } \\
\text { need to be more efficient } \\
\text { in reaching their targeted } \\
\text { populations (those in } \\
\text { desperate need of help) } \\
\text { Enhanced public health } \\
\text { education } \\
\text { Generators as a backup } \\
\text { power source } \\
\text { Making disinfection } \\
\text { widespread }\end{array}$ \\
\hline $\begin{array}{l}\text { Higher usage of } \\
\text { chlorine for disinfection }\end{array}$ & $\begin{array}{l}\text { Higher levels of } \\
\text { disinfection by- } \\
\text { products in treated } \\
\text { water }\end{array}$ & Potential side effects & $\begin{array}{l}\text { Impacts of by-products } \\
\text { should be monitored } \\
\text { Enhanced education }\end{array}$ \\
\hline $\begin{array}{l}\text { Stores stocked } \\
\text { necessities (like bottled } \\
\text { water) }\end{array}$ & Supply shortages & $\begin{array}{l}\text { Price gouging for basic } \\
\text { necessities (like bottled } \\
\text { water) }\end{array}$ & $\begin{array}{l}\text { Diversified water sources } \\
\text { Alternate delivery } \\
\text { strategy } \\
\text { Promote community } \\
\text { vigilance } \\
\text { Encourage reporting via } \\
\text { hotlines } \\
\text { Promote enforcement of } \\
\text { anti-price gouging laws } \\
\text { Educate consumers to } \\
\text { record violations }\end{array}$ \\
\hline $\begin{array}{l}\text { Water treatment } \\
\text { facilities }\end{array}$ & $\begin{array}{l}\text { Potentially damaged } \\
\text { Flooding may pollute } \\
\text { water }\end{array}$ & 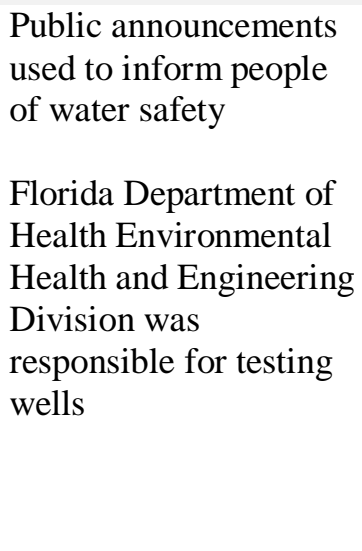 & $\begin{array}{l}\text { Redundancy - assures } \\
\text { uninterrupted potable } \\
\text { water service } \\
\text { Storage Capacity - avoid } \\
\text { wastewater treatment } \\
\text { plant (WWTP) overload. } \\
\text { Structural Integrity - } \\
\text { function properly } \\
\text { Backup Power and } \\
\text { Structural Stability }\end{array}$ \\
\hline
\end{tabular}


Bostrom et al. (2018) analyzed public perception of hurricane forecasts. At the end of their work, they explain that hurricane information dissemination could be improved. What is needed is a deeper understanding of residents' perceptions of their vulnerabilities. The thesis contributed to this by determining respondents' perceptions of their own preparedness and vulnerabilities.

Khan et al. (2015) examined the effects of severe weather on water quality. They concluded that: "Recently experienced water quality impacts from extreme weather events have revealed the need for improvements," and expressed the need "that future revisions of drinking water management guidelines pay particular attention to the management of water quality impacts associated with extreme weather events." The thesis research addressed this by recommending improvements where it found they were needed, and exploring the effectiveness of drinking water management via survey.

The literature review supported this study's argument: current efforts in dealing with hurricane-induced drinking water scarcity were found to be lacking. These deficiencies need to be addressed in order to develop robust preparations and response plans that can contend with the violent hurricanes that Florida experiences so frequently. This will help to avoid future public health crises and human suffering.

With this knowledge in hand, it remained to be seen whether people's experience with Hurricane Irma indicated the need for any of these potential improvements. The results of the survey clarified what kind of action(s) were needed to enhance resilience in the study area. 


\section{CHAPTER THREE:}

\section{STUDY AREA}

Counties were selected within Florida based on proximity to the coastline which influenced their vulnerability to severe storm damage. To maintain the economic feasibility of this research, the study area was kept to four counties. These counties were: Miami-Dade County, Collier County, Lee County, and Hillsborough County. The selected counties are found at the mid-west and southern portions of the peninsula (Figure 2). These counties are among the top sixteen most heavily populated counties in Florida (FloridaDemographicsbyCubit, 2017). They all border the coast — making them more susceptible to storm surges and flooding. They are similar in their language vulnerability (Figure 3), but differ in their socioeconomic vulnerability (Figure 4) (Schroeder, 2017). Language vulnerability is associated with the language barriers experienced by those who are not fluent in English. The results of this study were meant to be extrapolated to the study population.

\subsection{Miami-Dade County}

Miami-Dade County is the most populated county in Florida (FloridaDemographicsbyCubit, 2017). As of July 2017, the population was estimated to be 2,751,796 people (United States Census Bureau, 2017). Approximately $68.6 \%$ of this population is categorized as Hispanic or Latino, $13.2 \%$ is Caucasian, $18.2 \%$ is Black, $0.3 \%$ is Native 


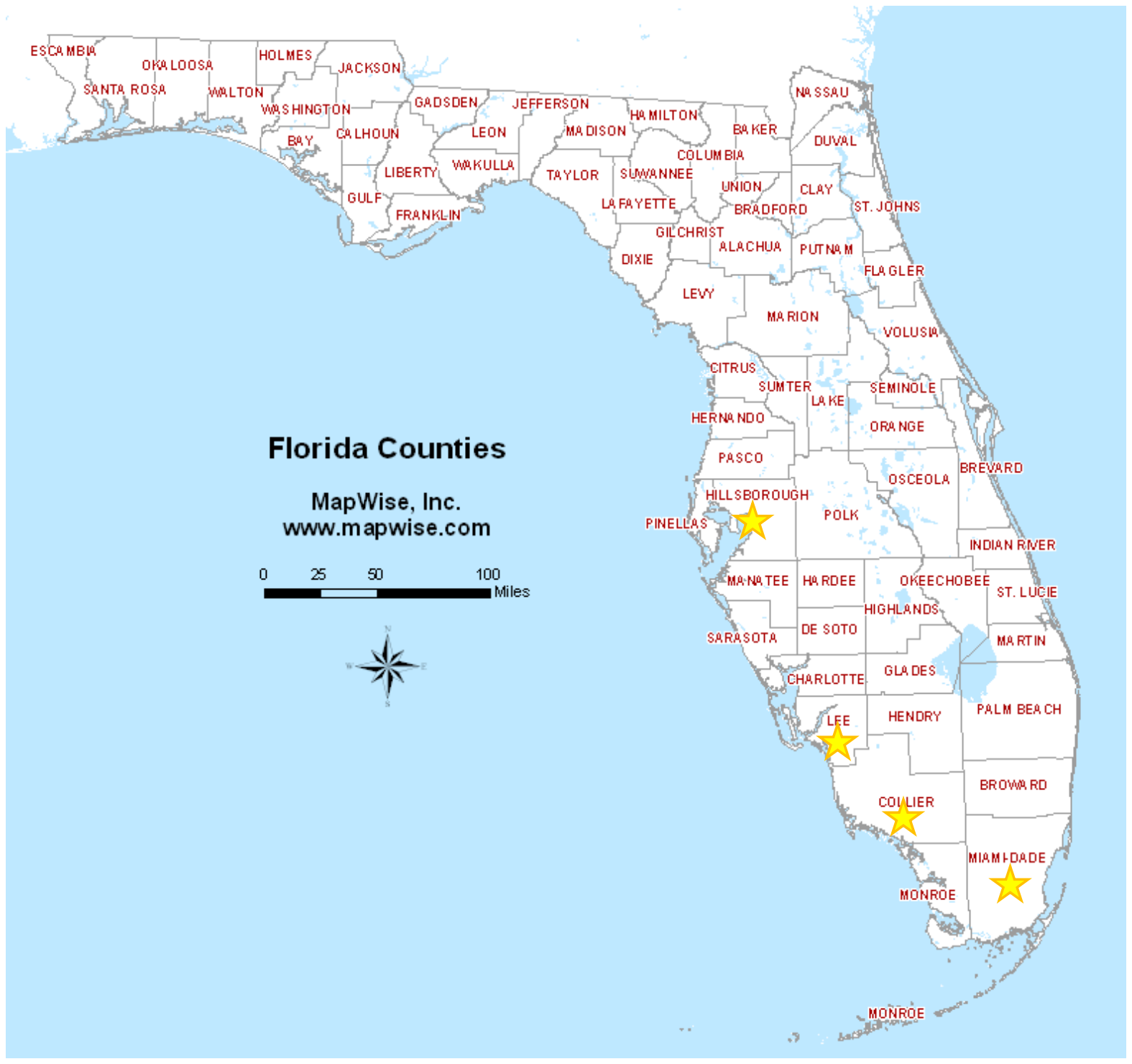

Figure 2: Map of counties in Florida. The counties selected for this research are marked with gold stars. Hillsborough, Lee, and Collier County have a coastline on the Gulf of Mexico on the western side of the peninsula. Miami-Dade County has a coastline on the Atlantic Ocean in the south-eastern part of Florida ("MapWise," 2018). 


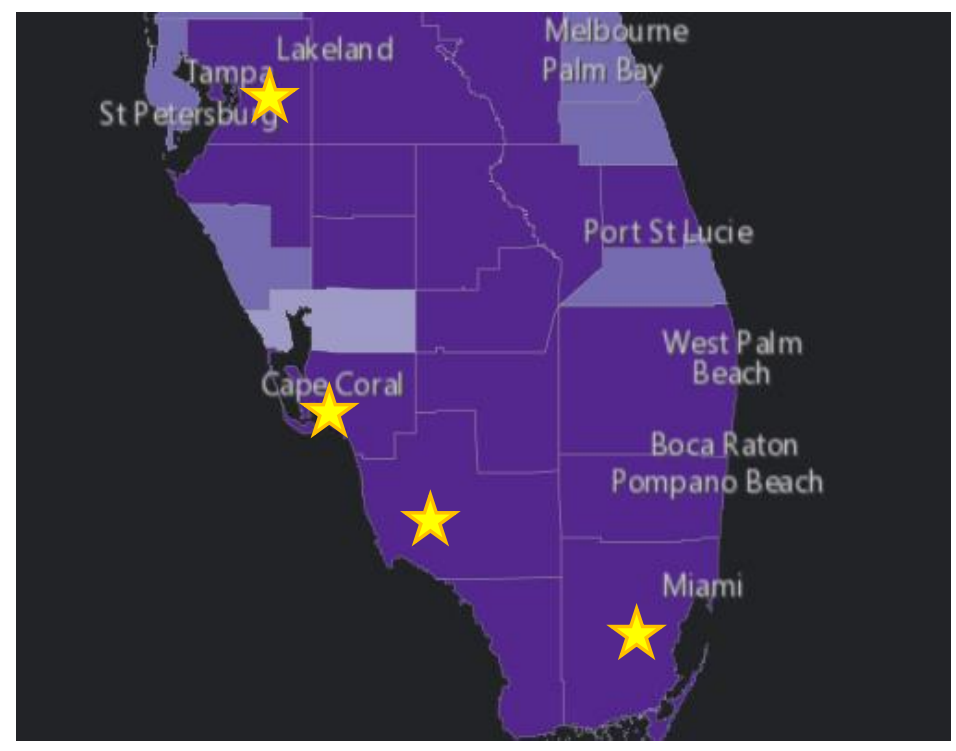

Figure 3: Map of language vulnerability of various counties in Florida. The counties selected for this research are marked with gold stars. The map scale goes from light to dark purple with greater vulnerability seen in counties that are darker purple (Schroeder, 2017).

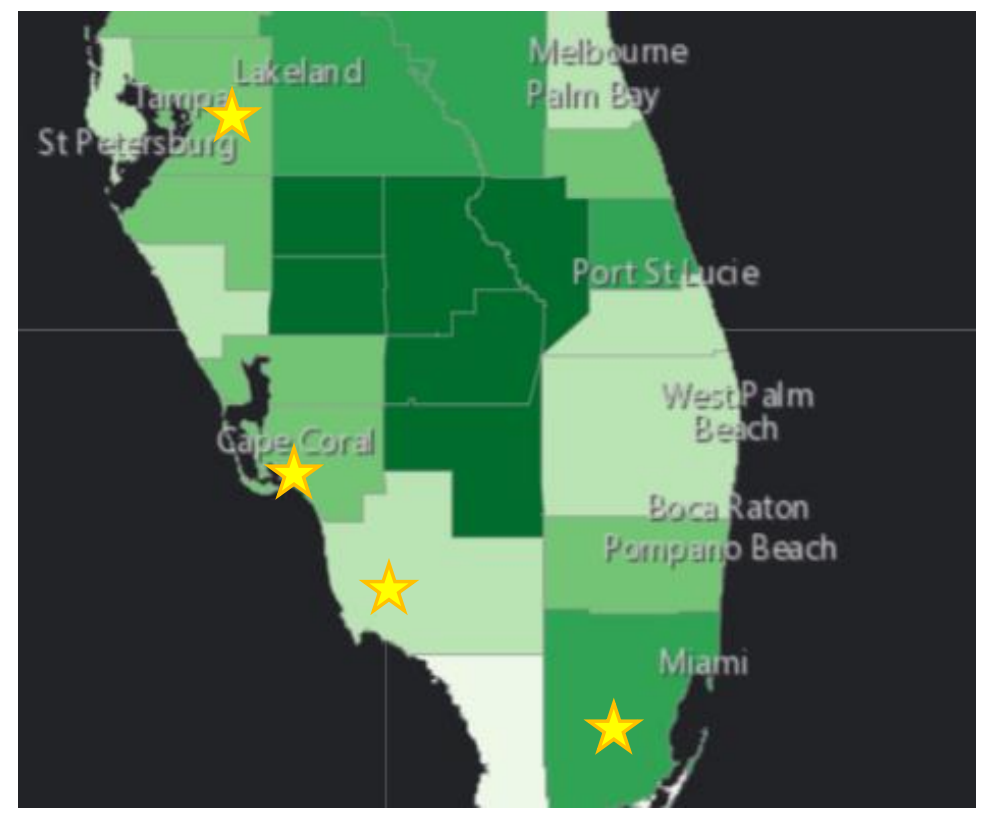

Figure 4: Map showing the socioeconomic vulnerability of various Florida counties. The counties selected for this research are marked with gold stars. The scale goes from light to dark green with greater vulnerability found in more darkly shaded counties (Schroeder, 2017). 
American, and $1.6 \%$ is Asian. About 27.3\% have a bachelor's degree education or greater (United States Census Bureau, 2017). The percentage of people living in poverty is estimated to be $18.2 \%$ (United States Census Bureau, 2017). Hurricane Irma caused 1585 homes to be damaged (National Weather Service, 2017).

\subsection{Collier County}

Collier County is the sixteenth most populous county in Florida (FloridaDemographicsbyCubit, 2017). The population is estimated to be 372,880 people (United States Census Bureau, 2017). This population is estimated to be $27.8 \%$ Hispanic or Latino, $63 \%$ Caucasian, 7.4\% Black, 0.5\% Native American, and 1.5\% Asian (United States Census Bureau, 2017). Approximately $33.9 \%$ of the population has a bachelor's degree or greater (United States Census Bureau, 2017). It is estimated that $11.4 \%$ people here live in poverty (United States Census Bureau, 2017). Hurricane Irma destroyed 88 structures and severely damaged 1500 more (National Weather Service, 2017).

\subsection{Lee County}

Lee County is the eighth most populated county in Florida (FloridaDemographicsbyCubit, 2017). This county's population is estimated at 739,224 people (United States Census Bureau, 2017). About $21.2 \%$ of the population is categorized as Hispanic or Latino, $67.5 \%$ is Caucasian, $9.1 \%$ is Black, $0.5 \%$ is Native American, and $1.7 \%$ is Asian (United States Census Bureau, 2017). Approximately $26.7 \%$ of the population has a bachelor's degree education or more (United States Census Bureau, 2017). It has been estimated that $12.8 \%$ of the population lives in poverty (United States Census Bureau, 2017). Hurricane Irma caused 89 homes to be destroyed and about 3,000 properties were damaged (Smith, 2017). 


\subsection{Hillsborough County}

Hillsborough County is the fourth most populated county in Florida (FloridaDemographicsbyCubit, 2017). The population of this county has been estimated to be $1,408,566$ people (United States Census Bureau, 2017). About $28.6 \%$ of this population is Hispanic or Latino, $49.1 \%$ is Caucasian, $17.8 \%$ is Black, $0.5 \%$ is Native American, and $4.3 \%$ is Asian (United States Census Bureau, 2017). Approximately $31.4 \%$ of the population has a bachelor's degree education or greater (United States Census Bureau, 2017). In this county, about $15 \%$ of the people live in poverty (United States Census Bureau, 2017). Hurricane Irma caused approximately a dozen homes to be destroyed and over 300,000 homes lost power (Taylor, 2017). 


\section{CHAPTER FOUR:}

\section{RESEARCH DESIGN}

\subsection{Research Question, Hypothesis, Problem Statement}

This study answered the overarching research question: With regard to preparation and emergency response, are water management policies effective at promoting resilience of potable water supplies in the event of hurricanes? This research question encompasses multiple subquestions:

1) To what extent did people in the selected counties experience drinking water shortages?

2) How long did these drinking water shortages last?

3) How could drinking water shortages have been avoided?

4) Do the reviewed water management practices accomplish their goals effectively?

It was hypothesized that current potable water policies, preparations, and emergency responses for hurricanes are insufficient due to the publicized water shortages people experienced during Hurricane Irma.

This insufficiency represents a serious problem for human health in the face of hurricanes. If potable water supplies are not resilient enough to withstand the effects of hurricanes, then the people will be (and have been) subject to water shortages that threaten their 
wellbeing. To this end, a survey concerning drinking water during Hurricane Irma was performed on the residents of Miami-Dade, Collier, Lee, and Hillsborough counties. This provided data to gauge the efficiency of said water management practices. Interpretation of resulting data indicated potential improvements in potable water management. This would help to alleviate the stress of drinking water shortages and reduce human suffering in future severe storms.

\subsection{Goals and Objectives}

The goal of this study was formed in two parts: 1) To identify areas of deficiency in policies, preparedness, and emergency responses to hurricanes with regard to potable water supplies and 2) To determine potential means of increasing potable water supply resiliency in the event of hurricanes. Resiliency is to be increased by identifying potential improvements in both short-term (emergency responses) and long-term (preparedness) efforts addressing drinking water paucity.

The objective of this study was to improve the resiliency of potable water supplies in the event of hurricanes for the benefit of human health and water security in the selected Florida counties. Ultimately, this was meant to contribute to minimizing human suffering.

\subsection{Rationale and Justification}

\subsubsection{Intellectual Merit}

The results are significant to the field of environmental science and the field of natural hazards as they concern how to safeguard human wellbeing from natural disasters. At the same time, the results are also significant to various other fields such as public health (drinking water is vital to health), economics (potential improvements may require investments and funding), and 
social science (improvements may require behavioral changes). In this way, this research advanced knowledge and understanding across multiple fields; thus, networking and partnerships between representatives of different disciplines could be facilitated. This study promoted scholarly discussion on the topic of severe storm impacts on drinking water that will enhance education. This research also explored creative and original concepts in that it specifically focused on the impacts of hurricanes on potable water supplies. There was little scholarly work that considered severe storms in conjunction with drinking water. Furthermore, this thesis studied the impacts of Hurricane Irma for which there was yet little data. This research was conceived as an exploratory investigation to determine the resiliency of potable water supplies by analyzing the effectiveness of potable water policies during Hurricane Irma. The needed resources were sufficiently accessible for this study. There were eight months available which was adequate time to complete the work. There was sufficient scholarly material and information to build up background knowledge and understanding. This material was readily accessible via the University of South Florida campus library and the internet. The necessary resources, such as the services of the Qualtrics Company, were accessible and available to complete the survey.

\subsubsection{Broader Impacts}

In the event of a hurricane, availability of survival resources dwindle due to insufficient stocks, hoarding by the general public, potential inaccessibility, contamination, and damaged supplies among other causes. Potable water is a crucial resource to human health and is one of the first, if not the first, of resources to be depleted. It is imperative that populations are effectively prepared for potable water paucity in the face of severe storm impacts.

The thesis research has a number of desirable societal outcomes and benefits society because: 
1) The knowledge gained from this study enables more effective hurricane preparations to be made.

2) Another benefit to society would be a reduction in drinking water shortages during severe storms.

3) The society can also benefit from more efficient distribution of drinking water resources in the event of a hurricane.

4) The results of the study can improve the efficacy of planning efforts for severe storms and help to illuminate priorities for future planning efforts.

5) The overall outcomes of the research help water managers and contingency planners to better allocate potable water, more efficiently manage this precious resource, and more effectively meet the needs of local residents.

6) Reducing the negative health impacts of hurricanes. The results of this work parse the nature of drinking water shortages experienced during Hurricane Irma and may help managers ensure a more adequate supply.

7) Encouraging greater efficiency in relief distribution thereby reducing wasteful resource use. The results from this research establish whether or not emergency relief allocation was wasteful. Recommendations to improve efficiency are made.

8) The society will benefit with regard to potable water as communities become more resilient to disturbances in supply. The study aided in this by identifying local drinking water supplies especially vulnerable to hurricane impacts.

9) Encouraging capacity building on the local level to contend with potable water shortages. A significant aspect of this is in promoting people's access to necessary 
resources (Abrams, 2003). This study accomplished this by gauging the accessibility of different water supplies and focusing efforts on those that could be more efficient.

This research improves society's wellbeing by promoting partnerships and cooperation between water managers, contingency planners, and academia. This will improve resiliency to disasters, water security, and also spare people from much misery and health concerns.

This study promotes sustainability in potable water management by encouraging better drinking water conservation. More effective preparation and planning along with an identification and reduction in wasteful distribution practices will bring about greater conservation. Furthermore, the survey and contribution to scholarly discussion will raise public awareness on the importance of water conservation as a direct influencer of human health. This heightened awareness will, in turn, focus greater attention on the sustainability of water reserves. 


\section{CHAPTER FIVE:}

\section{METHODS}

\subsection{Conceptual Framework}

The article "Household preparedness for the Aftermath of Hurricanes in Florida" by Baker (2011) provided a conceptual framework which was useful as a starting point from which to build this study's survey questions. The questionnaire discussed in this article was useful regarding the types of questions and answers that were suitable for this topic.

The conceptual framework was helpful in understanding how to measure respondents' preparedness for hurricanes. It consisted of four factors that contributed to the preparations that people make. These factors were: 1) Awareness 2) Availability of options 3) Perceived need and 4) Availability of resources.

Awareness involves people's knowledge of options to employ them. Residents have to know of what options exist in order to use them. Television and radio announcements can help to promote people's awareness. Newspapers and the internet also help in disseminating information. Governments may also promote awareness via public education.

Availability of options considers that preparation options need to be available for the public to make use of them. With respect to the proposed study, an example would be the availability of bottled water in stores. 
Perceived need involves the belief that preparation is necessary. This concerns people's worries about severe storms such as potentially negative health impacts and their desire to avoid shortages in necessities.

Availability of resources affects people's ability to apply preparation options. For example, residents may wish to purchase excess survival supplies. However, if funds are insufficient, then such preparations could not be made.

The preparation factors considered in this article (awareness of options, availability of options, perceived need, and resource availability) provided guidance for what questions to ask in this thesis research. This publication served as a beneficial example for the research by helping to guide the thought process and decisions made behind this study. It also gave an idea of what kind of relationships and behaviors may be found in respondents.

\subsection{Survey}

Once appropriate approval was obtained from the Institutional Review Board (IRB) at the University of South Florida, a survey was utilized to collect data from Florida residents about the impacts of Hurricane Irma on potable water availability (see Appendix A). This survey was created and administered online via the Qualtrics research company.

This research focused on four Florida counties. The study population consisted of the combined populations of the selected counties. From the chosen counties, people were surveyed via simple random sampling. The results from this survey can be extrapolated to the entire study area.

The study population consisted of the combination of populations from the selected counties: $2,751,796$ people $+372,880$ people $+739,224$ people $+1,408,566$ people $=5,272,466$ people. This is the overall population to which the research results can be extrapolated. 
Slovin's formula was utilized to calculate an appropriate sample size for this study as shown below (Statistical Methods, 2018):

$$
n=\frac{N}{1+N e^{2}}
$$

Where: $\mathrm{n}=$ sample size

$$
\begin{aligned}
& \mathrm{N}=\text { study population } \\
& \mathrm{e}=\text { margin of error }(5 \% \text { used here })
\end{aligned}
$$

This calculation yielded a sample size of 400 . This result was compared to results from three different online sources which yielded 384 (Creative Research Systems, 2012), 385 (SurveyMonkey, 2019), and 385 (Qualtrics, 2018) respectively. A larger sample size is preferable as it is more representative of the study population. Therefore, the sample size of 400 was the favored result. The thesis author was able to obtain a sample size of 535 respondents (Miami-Dade: 177, Collier: 105, Lee: 105, Hillsborough: 148).

The survey of multiple counties was accomplished via the research company, Qualtrics. The survey contained multiple choice questions some of which made use of the Likert rating scale. The Likert scale lets respondents indicate their level of agreement for a given statement. The scale may consist of five or seven points (a scale of five points was used for this study). Since people are more likely to complete shorter questionnaires, the number of questions in this survey was kept at thirty-four to promote a higher response rate.

The survey questions gauged the speed and efficacy of preparations and emergency responses to potable water issues caused by Hurricane Irma from the people's perspective. This provided a snapshot of drinking water resiliency. 
Online distribution allowed for faster dissemination of surveys and a more efficient means of tracking survey responses. It also meant that bias stemming from face-to-face surveys would not impact the results. Some segments of the population (for example, the poor and elderly) may be limited in their ability to access the internet. However, the proliferation of cellphones, tablets, and other devices capable of accessing the internet make online surveys more accessible today. This issue is further lessened, as compared to the past, with increasingly available broadband internet access.

Since this survey required respondents to recall events that occurred in a prior hurricane season, the accuracy of their responses was a potential concern. To address this, the questions were written in a way that would attempt to trigger strong responses from respondents' memories. Water is generally held as a priority among people readying themselves for a coming storm. Much effort goes into its acquisition and securing a sizable reserve that can, hopefully, last the length of the disaster period. Furthermore, when water supplies dwindle people may grow worried, and this stress is not easily forgotten. Running out of water would mean having to stand in long lines to obtain more - along with other unusual situations - and this would also not be forgotten easily. Care was taken so that each question could be understood clearly and did not cause discomfort to the respondent (as that may influence the answer given). The answers to multiple choice questions were made as clear as possible with many questions having the option for respondents to specify another response (allowing them to type in their own answers).

\subsection{Data Analysis}

The data collected from the survey was then analyzed, their meaning to this research was interpreted, and the results were summarized for ease of communication. Data analysis was performed by employing Cross Tabulation for Multivariate Analysis. There were multiple 
benefits to using cross tabulations in this research. This method not only helped to summarize the data, but it also enabled the identification of relationships between different factors and promoted the finding of potentially hidden relationships in the survey data. Where applicable, the arithmetic mean, median, and mode for the data were also calculated. These values were interpreted to gain insight into the respondents' perspectives.

For any inefficiencies found in potable water management (preparations and emergency responses), a rational decision-making model was employed as a guide to logically identify potential improvements or solutions. This procedure was used to choose the best options for improvement in order to make recommendations. Such a model for decision-making has been discussed in scholarly literature (Krumboltz, Scherba, Hamel, \& Mitchell, 1982). This approach involved the following steps:

1) Define the issue at hand

2) Establish a plan—-for the purposes of this research, the plan concerned creating decision-making criteria

3) Determine values - for this research, this step meant ranking the criteria to determine which was most significant

4) Identify options

5) Evaluate options

6) Eliminate poorer options (based on criteria)

7) Choose best option(s) to put into action 
The decision-making criteria and options were formulated by using this model in conjunction with the conceptual framework from the article by Baker (2011). The conceptual framework consisted of four key factors: 1) Awareness 2) Availability of options 3) Perceived need 4) and Availability of resources. The criteria evaluated options for improvement with regard to these factors. In this way, the options that best promoted these factors could be determined. This helped to guide the direction of proposed improvements. 


\section{CHAPTER SIX:}

\section{RESULTS}

\subsection{RQ1: To What Extent did People Experience Potable Water Shortages?}

Demographics and county data were perused to determine the extent of drinking water shortages and to see if any group(s) were more heavily impacted. Cross tabulation was used to construct tables displaying column percentages for the data. As a reminder, the population size was 5,272,466 and the sample size was 535 (Miami-Dade: 177, Collier: 105, Lee: 105, Hillsborough: 148). The chi-square test was used to determine the statistical significance of relationships between variables; statistically significant results were shown in the tables (Table 4) (Table 5) (Table 6). Yellow highlighting was used to denote observations important to this study. Significance was determined for cases where the p-value was equal to or less than the alpha level of 0.05 .

\subsection{RQ2: How Long did These Shortages Last?}

Data pertaining to the number of respondents and the length of time they experienced various water shortages was graphed (Figures 5-8). These graphs depicted the number of respondents affected by different types of water shortages. Time spans (days without water) were categorized for organizational purposes. The categories included:

a) Not applicable

b) 0 days (Those who did not lose their potable water) 


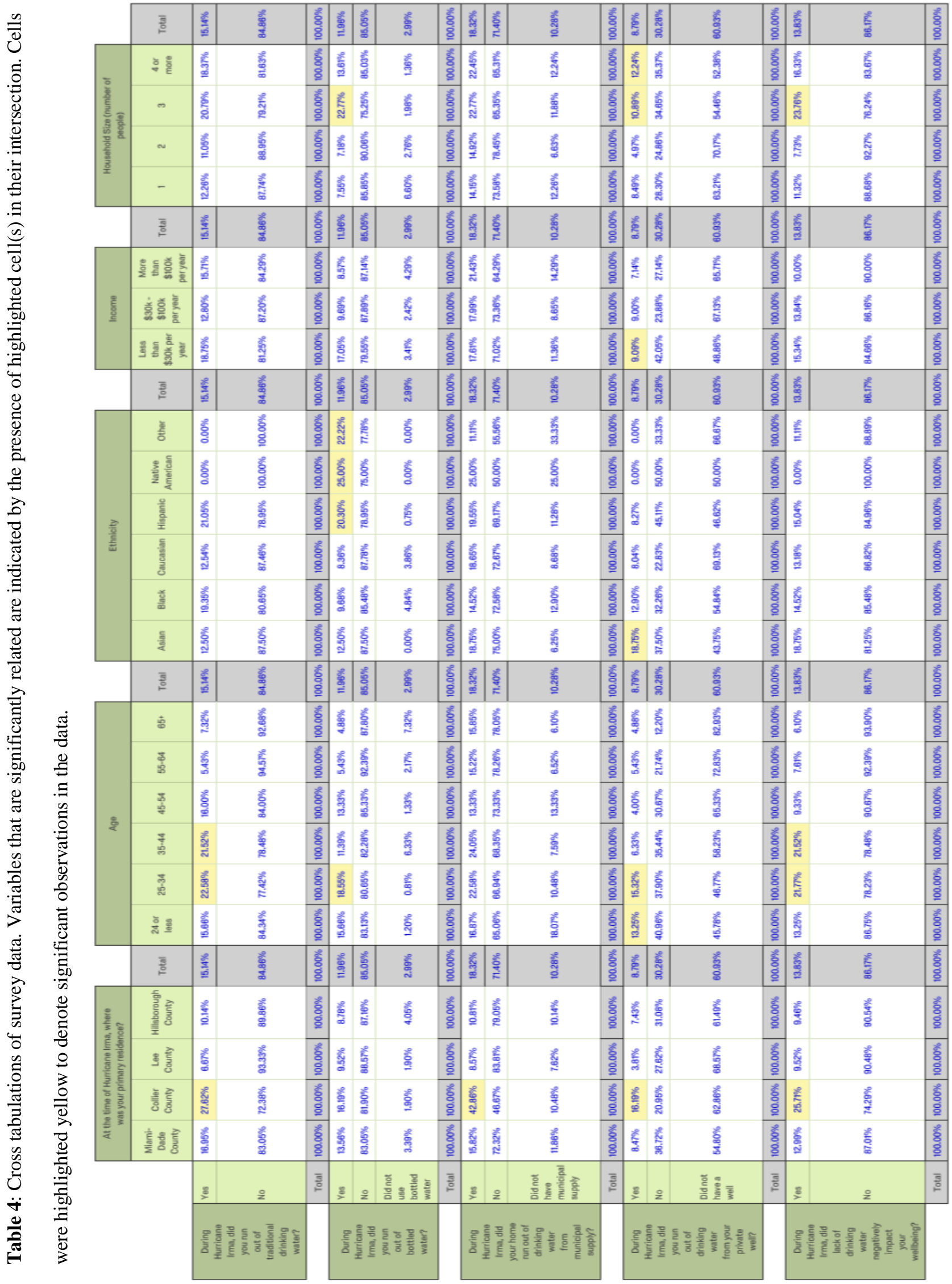



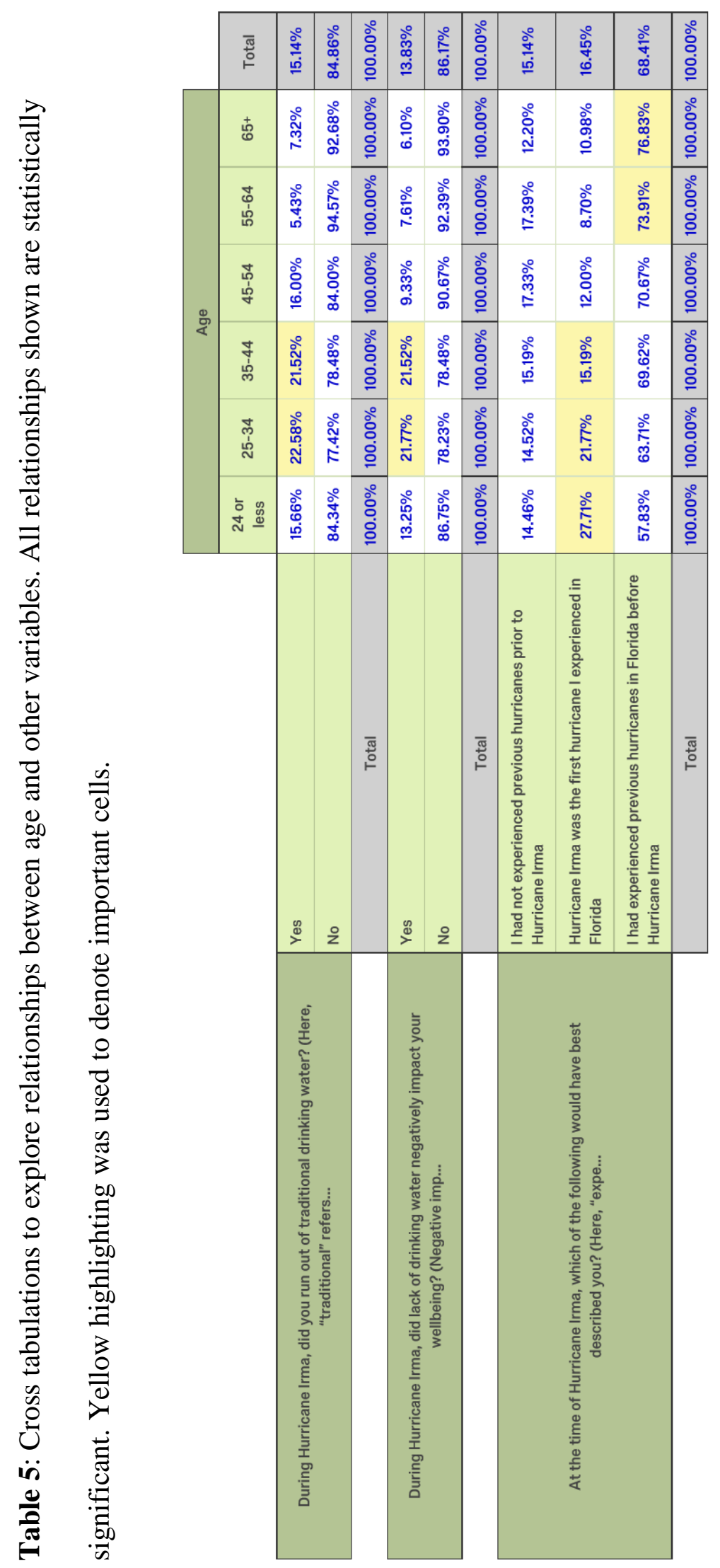

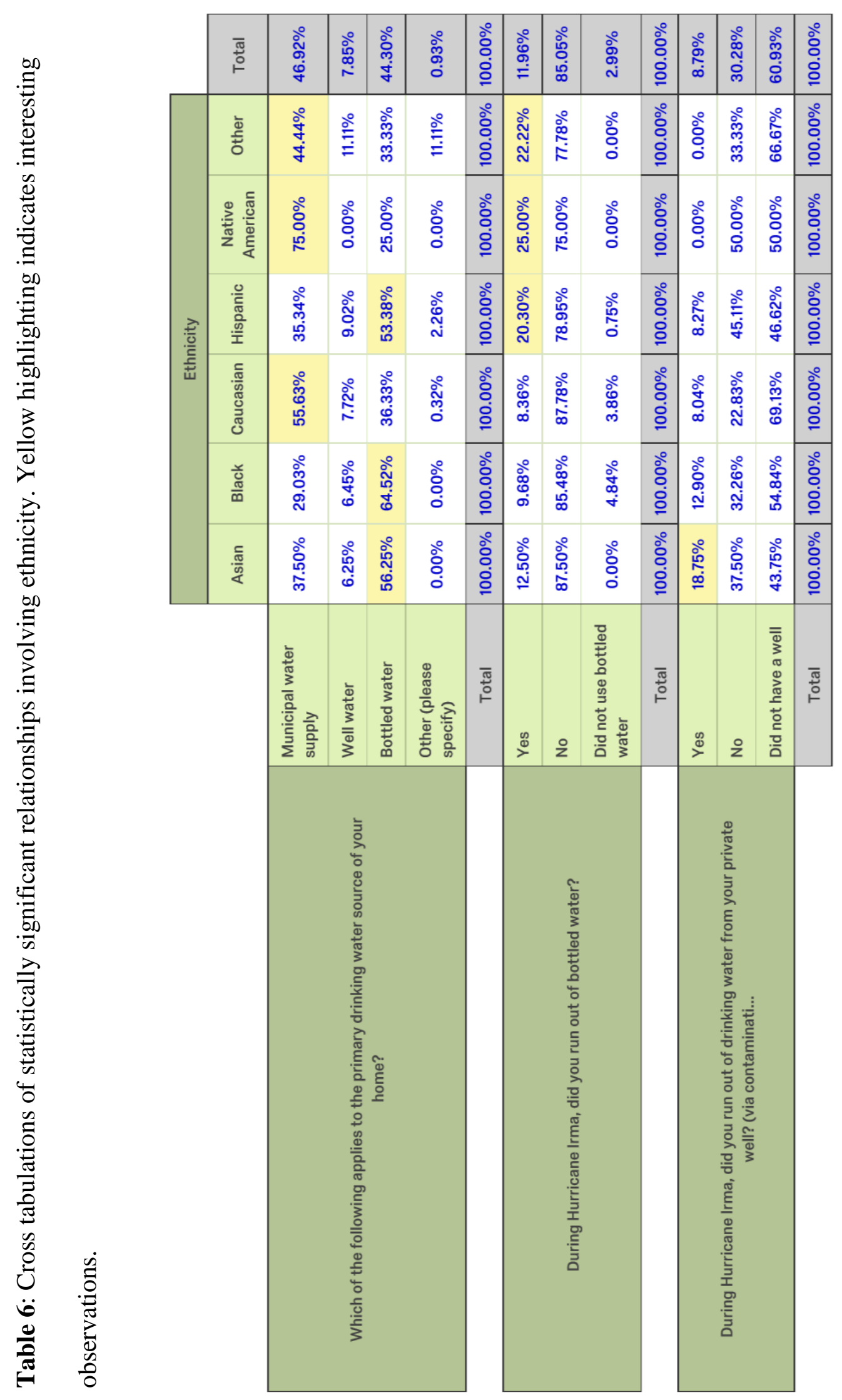
c) 1-3 days (An important time span since much preparation education informs people to be ready to last three days without access to their usual water supplies)

d) More than 3 days but still less than a week

e) A week (Miami-Dade County advises residents to stock enough drinking water to last three to seven days)

f) More than a week, up to 2 weeks

g) More than 2 weeks, up to a month

h) More than a month

The mean, median, and mode were determined for each dataset that pertained to various water shortages. For each of these calculations, "N/A" responses were excluded. These values were provided next to their corresponding graphs below.

The number of respondents who experienced potable water shortages for greater than three days was investigated. For bottled water, $114(\sim 21.3 \%)$ out of all 535 respondents experienced shortages that lasted more than three days. The mean was 2.69 days, the median was 1 day, the mode was 0 days, the Minimum was 0 days, and the maximum was 90 days. For municipal water, $105(\sim 19.6 \%)$ out of all respondents experienced shortages that lasted beyond three days. The mean was 2.70 days, the median was 0 days, the mode was 0 days, the minimum was 0 days, and the maximum was 263 days. For private well water, $36(\sim 6.73 \%)$ out of all respondents experienced shortages for greater than three days. The mean was 2.28 days, the median was 0 days, the mode was 0 days, the minimum was 0 days, and the maximum was 90 days. In terms of access to all traditional drinking water (defined in the survey as water that is ready to drink with no treatment needed), $144(\sim 26.9 \%)$ out of all respondents experienced shortages for more than three days (51 Miami-Dade residents, 49 Collier residents, 31 Lee 
residents, and 13 Hillsborough residents). The mean was 2.93 days, the median was 2 days, the mode was 0 days, the minimum was 0 days, and the maximum was 42 days. In general, most respondents reobtained their water supplies in three days. However, others had to wait for weeks or even months.

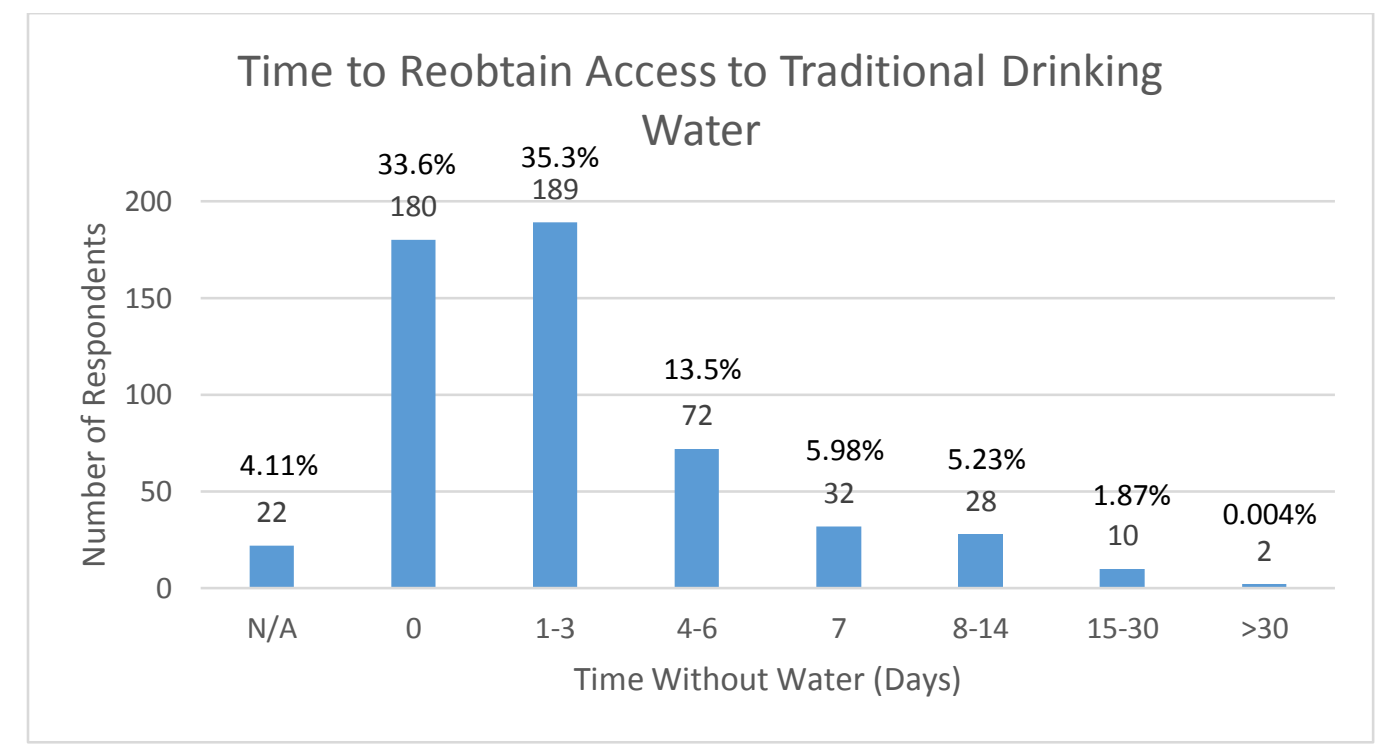

Figure 5: Data for number of respondents and the time required to reacquire potable water. Both the number of people and their equivalent percentages were provided above each bar. Other statistics: Mean: 2.93 days, Median: 2 days, Mode: 0 days, Min: 0 days, Max: 42 days.

\subsection{RQ3: How Could These Shortages Have Been Avoided?}

Respondents' perceptions of their risk and vulnerabilities were investigated (Table 7). There was a statistically significant relationship between people's perceived preparedness and their actual preparedness. In general, those who believed themselves adequately ready for the hurricane really were sufficiently prepared. 


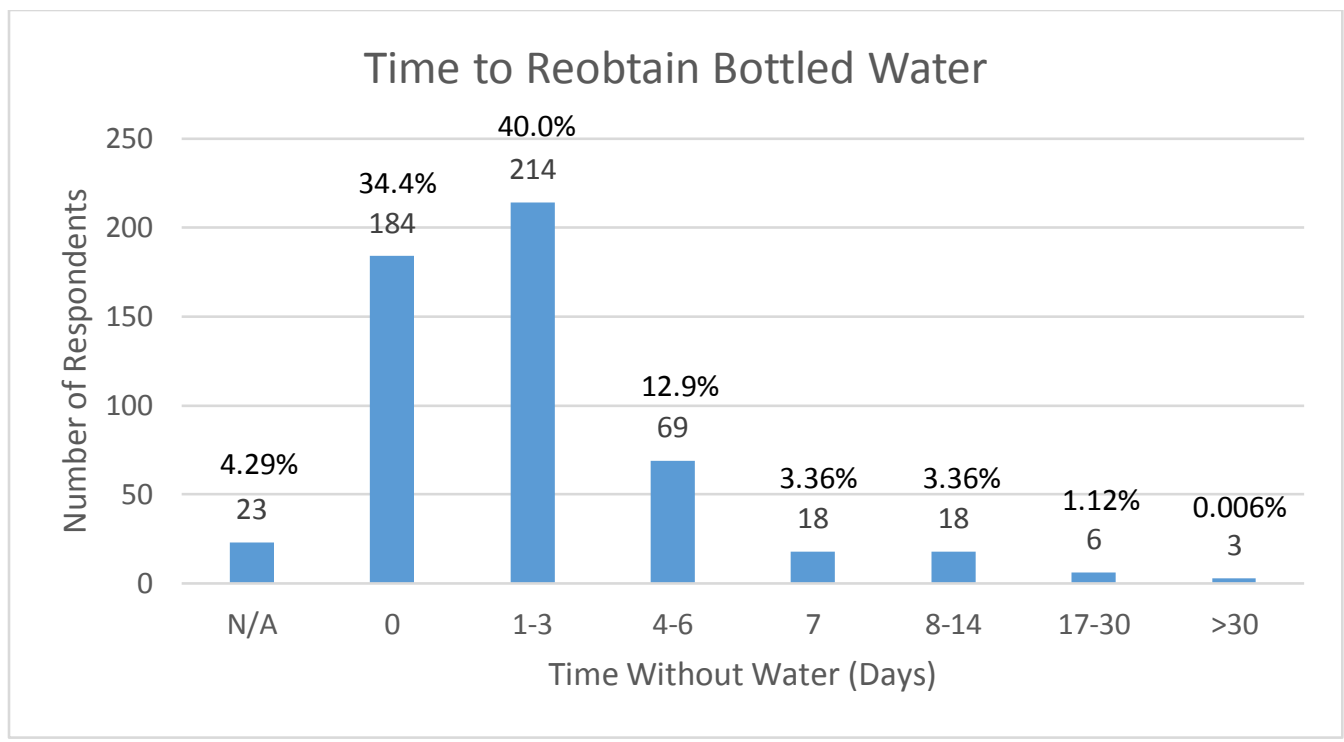

Figure 6: Data for number of respondents and the time it took them to reacquire bottled water.

Both the number of people and their equivalent percentages were provided above each bar. Other statistics: Mean: 2.69 days, Median: 1 day, Mode: 0 days, Min: 0 days, Max: 90 days.

A cross tabulations table was used to determine statistically significant relationships between age, ethnicity, water treatment methods used, and information source for treatment methods (Table 8). Younger respondents (below 45 years old) were more likely to use popular treatment techniques (chlorine, iodine, boiling, disinfection tablets). The use of boiling for disinfection was relatively more widespread than other methods. In general, Native Americans were more inclined to use disinfection techniques than other ethnic groups. Again, boiling for disinfection was widespread across all ethnicities to treat water. The elderly were more likely to select the "Other" answer choice with regard to treatment methods. For the most part, the older respondents that selected "Other" indicated that they actually had not utilized any treatment methods, some preferred to rely on bottled water, and a few indicated the use of filters. 


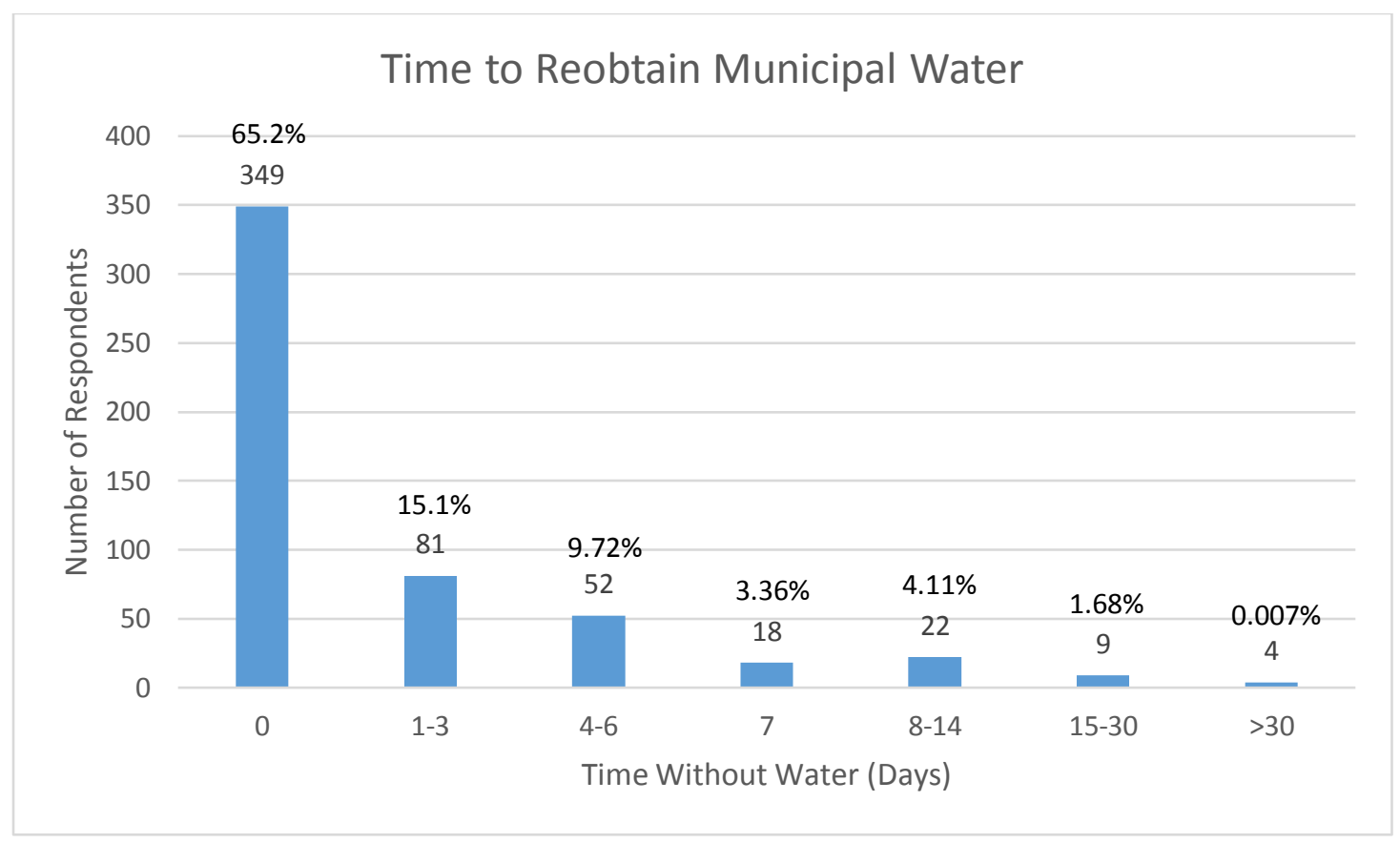

Figure 7: Data for number of respondents and the time required to reobtain municipal water. Both the number of people and their equivalent percentages were provided above each bar. Other statistics: Mean: 2.70 days, Median: 0 days, Mode: 0 days, Min: 0 days, Max: 263 days (Note: The N/A answer was not selected by respondents and, thus, does not appear in the graph as it would have a value of zero).

With regard to primary information source, the favored source differed between different age groups. Younger respondents mostly obtained information regarding water treatment from radio, internet, and social media. On the other hand, more elderly people seemed to prefer word of mouth, television, and other sources (these included own knowledge, previous experience, and a community emergency radio network). 


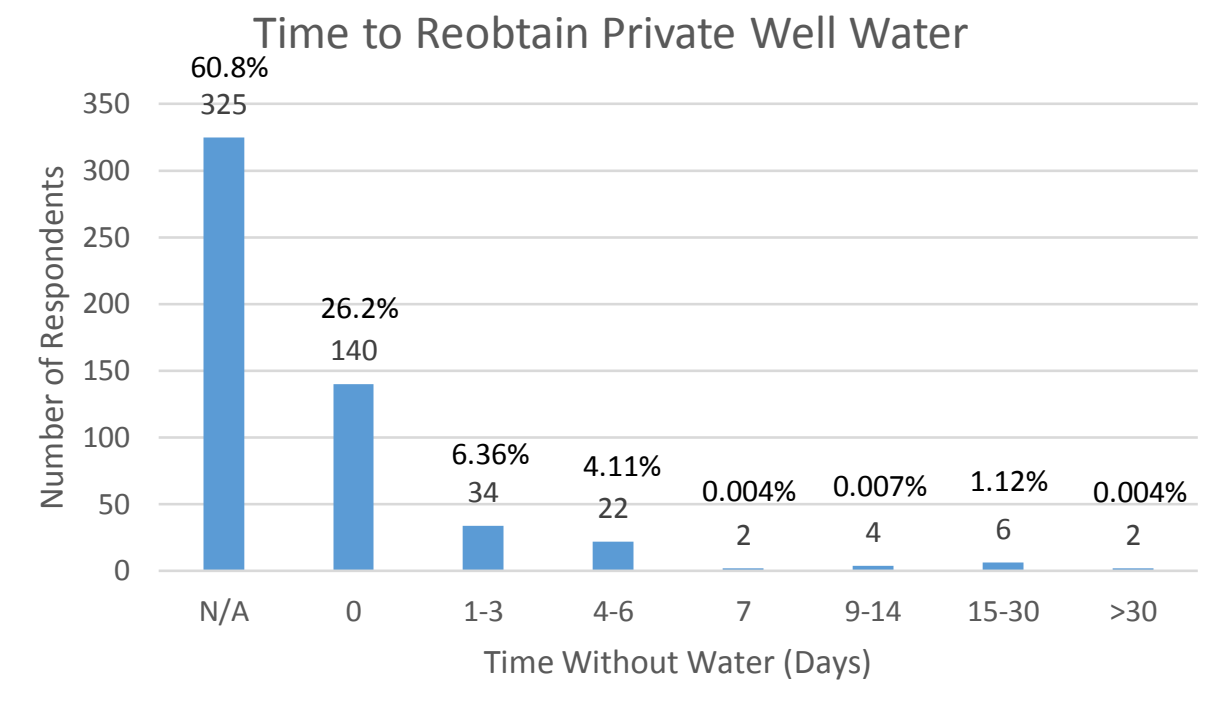

Figure 8: Data for number of respondents and the time needed to reacquire potable water from private wells. Both the number of people and their equivalent percentages were provided above each bar. Other statistics: Mean: 2.28 days, Median: 0 days, Mode: 0 days, Min: 0 days, Max: 90 days.

\subsection{RQ4: Do Management Practices Accomplish Their Own Goals Effectively?}

Cross tabulations were done for data pertaining to the receiving of emergency relief and - very importantly - the necessity of the aid (Table 9). Data regarding satisfaction with aid was graphed (Figure 9). Of all respondents who received drinking water from relief supplies from the city, most of them found the aid satisfactory. In general, at the county, state, and federal levels, most of the people who received relief were satisfied with the aid. Finally, with regard to being in absolute need of potable water from relief supplies, it was found that fairly large proportions of respondents who received emergency relief actually did not need them. For the city, county, and state levels, over $20 \%$ of respondents who received relief did not need aid. 
For federal relief, relief from other sources, and relief from unknown source, very large proportions $(52.63 \%, 63.64 \%$, and $50 \%)$ of those who received relief did not need aid. 

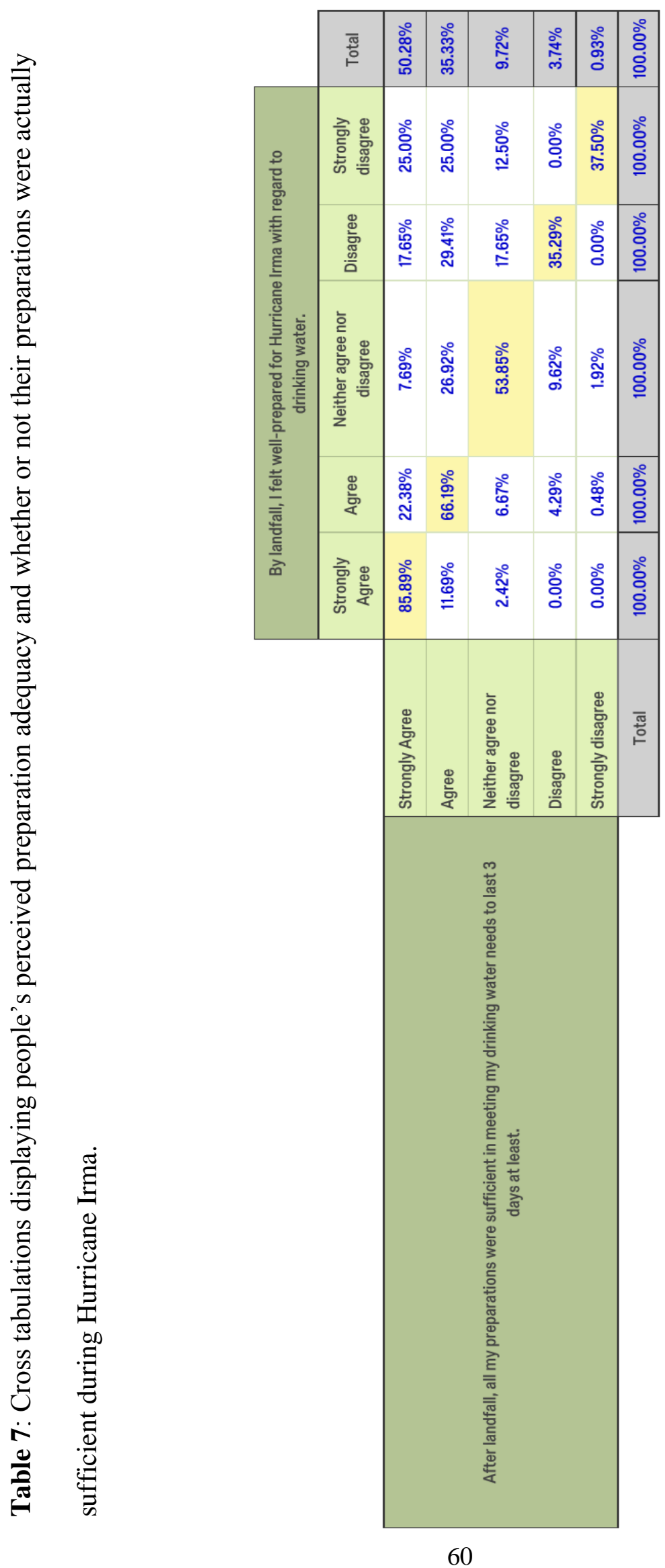


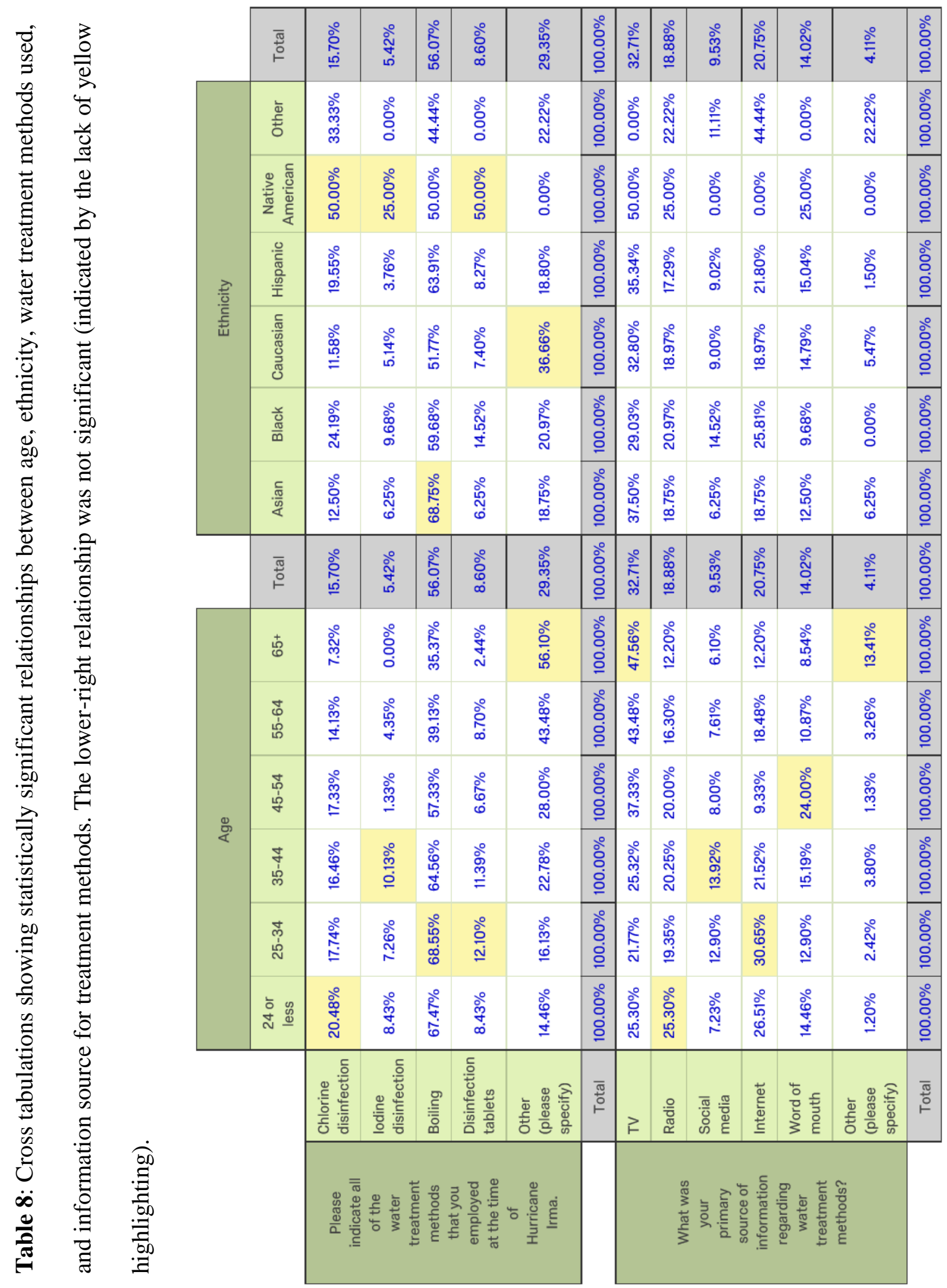




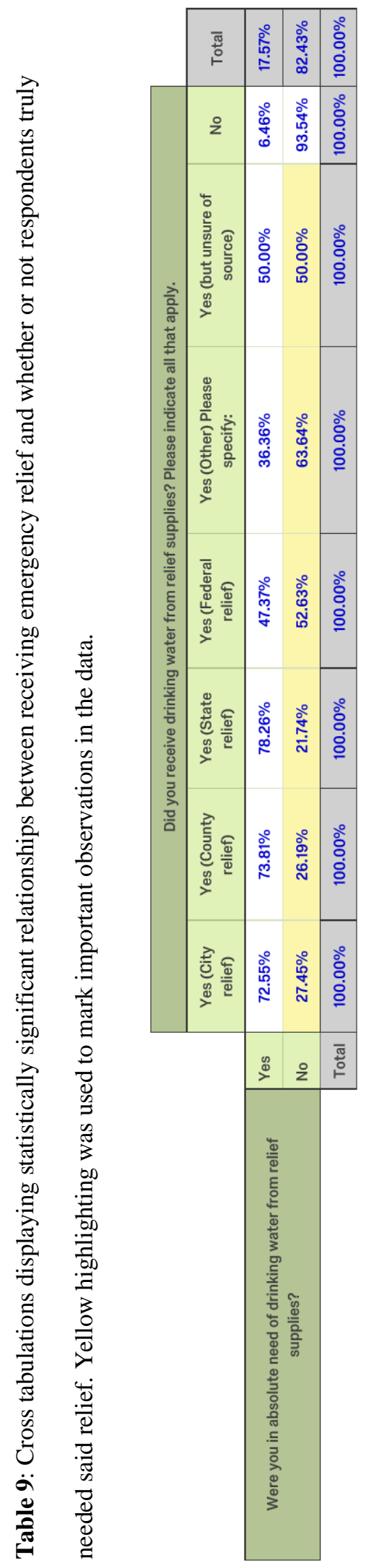




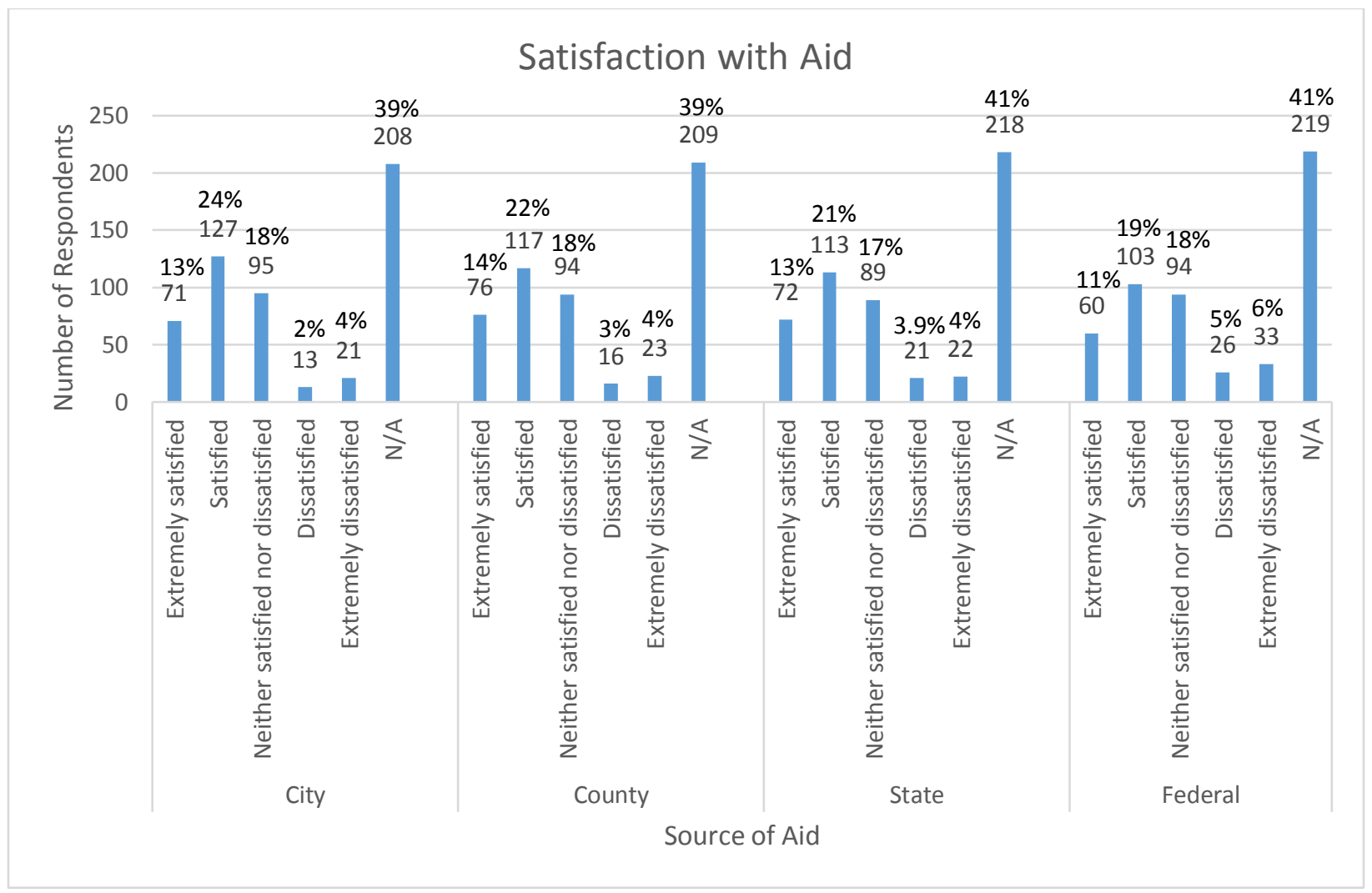

Figure 9: Data for respondents' satisfaction with aid by source. Most respondents found provided relief to be satisfactory regardless of source. 


\section{CHAPTER SEVEN:}

\section{DISCUSSION}

\subsection{Examining RQ1 - Extent of Potable Water Shortages}

From Table 4, it was found that county of primary residence was significantly related to whether or not people ran out of potable water. More than a quarter (27.62\%) of respondents from Collier County indicated a lack of drinking water during Hurricane Irma. This was the highest proportion out of all the counties. County of residence was also significantly related to the loss of water from municipal supplies. Here, Collier County once again stood out with the highest column percentage. Nearly half (42.86\%) of respondents indicated that they lost their municipal water. There was also a significant relationship between county residence and the loss of private well water. Collier County was most heavily impacted with $16.19 \%$ of its respondents stating they ran out of water from their wells. County residence was also significantly linked with harm to wellbeing as caused by a lack of potable water. Collier County was most heavily impacted in this regard $(25.71 \%)$. This implies that people residing in Collier County are more likely to experience insufficient reserves of potable water than residents of other counties in the study area.

Age was significantly related to losing traditional drinking water in general, running out of bottled water, losing private well water, and negative impacts on wellbeing. Young adult to middle aged respondents (ages 25-44) were more likely to have lost access to traditional drinking 
water. Younger people were also more likely to run out of bottled water, well water, and to have lack of potable water negatively impact their wellbeing.

Ethnicity was linked with running out of bottled water, and private well water.

Respondents who answered Hispanic, Native American, or Other were far more likely to have run out of bottled water $(20.3 \%, 25 \%$, and $22.22 \%$ respectively). Those who answered Asian were more likely to have run out of water from their private well (via contamination, etc.) than other ethnicities.

While it was found that income and running out of water from a private well were related, the differences between income levels was not particularly large. Low income $(<\$ 30,000$ per year) respondents were slightly more likely to be unable to use private well water.

Household size (or the number of people per household) was found to be significantly related to an inadequate supply of bottled water, private well water, and negative impacts on wellbeing. A household size of 3 was more likely to experience shortages in bottled water, household sizes of 3 or greater were more likely to experiences shortages in private well water, and a household size of 3 was more likely to experience negative impacts to human wellbeing as a result of drinking water shortages.

While some of these relationships make sense (such as larger households being more likely to be affected by drinking water shortages than smaller households, larger households being more likely to be negatively impacted by water shortages, and lower income people being at a greater disadvantage), some of the observed relationships can be highlighted for further interpretation.

Younger respondents were more likely to encounter drinking water shortages that also negatively impacted their wellbeing. This may have been influenced by the experience (or lack 
thereof) that people accrued from dealing with past hurricanes (Table 5). It is interesting to note that older respondents were more likely to have experienced hurricanes in Florida before Hurricane Irma. On the other hand, a large proportion of younger people indicated that Hurricane Irma was the first hurricane they experienced in Florida. Having more experience in dealing with severe storms may afford older respondents greater knowledge of preparation measures. It would also give them motivation to pursue said measures - particularly if they had experienced water shortages in the past. This sheds light on the importance of previous disaster experience and addresses the contention by Baker (2011) that previous disaster experience was worthy of future research.

The observed relationship involving ethnicity points to a potential disparity between different ethnic groups (Table 6). This observation may have been influenced by socioeconomic factors. Respondents who answered "Native American" or "Other" used municipal water as their primary drinking water source. For this reason, they may not have prepared adequate stocks of bottled water and subsequently ran out of bottled water during the hurricane. Those who answered "Hispanic" primarily use bottled water as their water source, however, they were also likely to lack bottled water during the hurricane. This may be due to financial constraints preventing them from purchasing enough supplies. Respondents who answered "Asian" indicated that a large portion of them primarily used bottled water $(56.25 \%)$ whereas a small portion of them primarily used well water (6.25\%). At the same time, Asians were more likely to have had trouble with their private well water as compared to other ethnicities. This may have been due to their high reliance on bottled water. Since wells were not a major source of drinking water for these respondents, they may not have been too concerned with the water quality of their wells and, thus, were not too concerned with maintaining sanitary systems. 


\subsection{Examining RQ2 - Length of Shortages}

From the mean, median, and mode calculations, it appears that the respondents generally did not have to last beyond three days without their regular water supply. Most people did not lose their water supply or were able to reobtain it in less than a day. There were, however, some respondents who lost water for far longer than three days.

It is interesting to note that, with regard to reliable access to traditional drinking water, 144 of all respondents experienced shortages for greater than three days. This constitutes $26.92 \%$ of the total sample size. Extrapolating to the overall study population means that a little more than a quarter of the combined population of the four counties suffered from inadequate access to potable water for more than three days. This suggests that the policy of these counties to promote local preparedness to last three days without regular water supply was insufficient for these respondents. Even Miami-Dade County's policy of educating the public to prepare by stocking enough drinking water to last three to seven days was insufficient as many respondents indicated shortages lasting far beyond a week—some even over a month. Residents of Miami-Dade, Collier, and Lee counties were more heavily impacted while residents of Hillsborough County were less affected.

\subsection{Examining RQ3 - Avoiding Shortages}

It was found that respondents who believed themselves ready for the hurricane really were sufficiently prepared. Furthermore, those who believed themselves under-prepared really were inadequately prepared. This relationship suggests that people's perceptions of their own risks and vulnerabilities coincide fairly well with their true level of preparedness; shedding light on this aspect of hurricane preparations by addressing Bostrom et al. (2018) who called for a deeper understanding of people's perceptions of their own vulnerabilities. 
Younger respondents (below 45 years old) were more inclined to use typical treatment methods like chlorine, iodine, boiling, and disinfection tablets. Boiling for disinfection was relatively more popular than other techniques. It was found that Native Americans were more likely to have used disinfection techniques than other ethnic groups. Boiling was popular across all ethnic groups to treat water. Elderly respondents were inclined to choose the "Other" answer option with regard to treatment methods - mostly using it to indicate that they had not used any treatment methods (while some relied on bottled water, and a few used filters).

From the data for primary information source, it seems that primary source differed between differently aged respondents. Younger people mainly acquired information about water treatment from radio, internet, and social media sources. Elderly respondents preferred word of mouth, television, and other sources such as own knowledge, previous experience, and even a community emergency radio network.

Respondents ranging from young to middle aged (25-44 years old) were more likely to have lost access to traditional drinking water. Furthermore, younger people were more likely to run out of bottled water, well water, and have lack of potable water negatively impact their health.

From this, it appears that younger people's trouble with running out of water may be related to their favored sources of information. Younger respondents experienced more shortages in traditional drinking water and were more likely to lack bottled water, and well water. Although younger respondents were more inclined to use chlorine, iodine, boiling, and disinfection tablets to treat their water, lack of potable water was still more likely to negatively impact their wellbeing. 
It seems younger peoples' major information sources for water treatment (radio, internet, and social media) were insufficient to prepare them for the severe storm. This may be due to the nature of these information sources. These information sources, while useful for quick dissemination, may be unreliable depending on how people use them. Radio stations may broadcast useful information, however, young people may switch to music after or in the middle of the broadcast. Even if the music station itself provides hurricane information, the young listeners' focus may be on the music. The internet can communicate an array of knowledge relating to hurricane impacts and how to deal with them, however it relies on the user to spend enough time to find and read the information. The internet can also be a source of distractions. Young people may only skim the material before they turn their attention back to seemingly more "important" things such as videos, online shopping, games, and social media. Social media platforms are useful for spreading significant information addressing hurricane impacts, however like the internet, it requires users to spend enough time on relevant material. Instead, many young people primarily use it to stay up-to-date with current trends, social news, and gossip and give other material secondary attention at best.

On other hand, the primary information sources of the elderly may be more reliable in terms of instilling important information. The elderly made use of word of mouth, television, and other sources (personal knowledge, previous experience, and a community emergency radio network). Personal knowledge and previous experience are tied to familiarity with hurricanes and their impacts. This first-hand knowledge could have greatly aided older respondents as they already had practice in dealing with potable water scarcity caused by severe storms. Television channels can air short informational programs before the shows people want to watch. Word of mouth and the idea for a community emergency radio network may both stem from greater social 
involvement with others seasoned in hurricane impacts. Thus, it may be possible for younger residents to avoid potable water shortages by being more involved with the elders of their community and taking advantage of the elders' primary information sources. This would allow them to benefit from the elderly's advice, past experiences, and first-hand knowledge. These findings concur with Bostrom et al. (2018) who explained that hurricane information dissemination could be improved.

\subsection{Examining RQ4 - Accomplishing Management Goals}

For the most part, respondents felt satisfied with the relief they received. However, an interesting observation was made with regard to absolute need of drinking water from relief. Large proportions of respondents who received emergency relief did not need aid. Over $20 \%$ of respondents who benefited from emergency relief (from city, county, and state levels) did not actually need the aid. The percentages were even higher for federal relief, relief from other sources, and relief from unknown sources where $52.63 \%, 63.64 \%$, and $50 \%$ of people who received relief were not in need.

These results, along with the knowledge that people did experience drinking water shortages that harmed their wellbeing, suggest that emergency relief efforts could be more effective at helping their target populations. It is beneficial to have emergency relief as there are clearly people in need of such aid, but it would be even more beneficial if it could reach a larger number of those in absolute need. These findings address the call for future research by Chatterjee and Mozumder (2015) for studies to explore the efficiency of emergency relief in reaching their intended recipients. 


\subsection{Rational Decision-Making}

Finally, a rational decision-making model was used as a guide to determine recommendations for potential improvements in potable water management in the event of hurricanes. These improvements addressed the contention by Khan et al. (2015) who stated "that future revisions of drinking water management guidelines pay particular attention to the management of water quality impacts associated with extreme weather events." In doing so, the recommendations in this thesis may help to augment preparation and emergency response efforts in Miami-Dade, Collier, Lee, and Hillsborough counties.

\subsubsection{Step 1: Defining the Issue}

The first step was to define the drinking water issues or problems that occurred during Hurricane Irma as observed from this study's data. These issues were listed as follows:

1) Respondents who indicated "Hispanic" ethnicity used primarily bottled water as their water source, yet they were prone to lack bottled water during Hurricane Irma. This was possibly due to economic constraints limiting their purchase of supplies.

2) Asians were more inclined to experience issues with their private wells compared to other ethnic groups. Since wells were not their major source of drinking water, they may not have been concerned with their well water quality and so were not concerned with keeping sanitary systems.

3) More than a quarter of the four counties experienced insufficient access to drinking water for over three days. This implies that the counties' policies to promote local preparedness to last three days without regular water supply were inadequate.

4) Younger people experienced more shortages in traditional drinking water, bottled water, and well water. Younger respondents' lack of potable water was more likely to 
negatively impact their wellbeing. Younger respondents running out of water may be related to their preferred sources of information.

\section{5) A large proportion of people who received emergency relief did not actually need}

aid.

\subsubsection{Step 2: Create Decision-Making Criteria}

The next step was to form decision-making criteria that would be used to evaluate options for improvement. These criteria reflected the concept of resilience (defined in this thesis as: the ability of the system to promptly and effectively return to its original state after a disturbance) and the four factors of the conceptual framework (Awareness, Availability of options, Perceived

need, and Availability of resources). The recommended improvement options would have to help residents either maintain or re-acquire potable water. These improvements would have to:

- Be fast enough to meet the people's needs before water shortage(s) harms their wellbeing

- Effectively address shortages for as many people in need as possible

- Help make people more conscious of proper preparation measures and what actions to take if shortages occur

- Promote the availability of options so that residents may utilize them

- Promote people's perceptions of their own vulnerability to appropriately match their actual level of vulnerability

- Enhance the availability of resources which residents may use towards dealing with drinking water shortages

\subsubsection{Step 3: Rank Criteria}

The criteria were ranked by their ability to promote human health and wellbeing. The deficiencies found in short and long-term responses to water shortages during Hurricane Irma 
were kept in mind while comparing the criteria. The rankings were as follows from most to least important:

1) Be fast enough to meet the people's needs before water shortage(s) harms their wellbeing / Effectively address shortages for as many people in need as possible

2) Enhance the availability of resources which residents may use towards dealing with drinking water shortages

3) Help make people more conscious of proper preparation measures and what actions to take if shortages occur

4) Promote the availability of options so that residents may utilize them

5) Promote people's perceptions of their own vulnerability to appropriately match their actual vulnerability

\subsubsection{Step 4: Identify Options}

Options for improving potable water management in the event of hurricanes were researched and found in the scholarly literature. Readers can refer to Table 3 (the right-most column) for a list of options found in scholarly literature with potential for reducing potable water shortages and their negative impacts. These will not be repeated here for sake of brevity.

\subsubsection{Step 5: Evaluate Options}

For issue \#1 (financial constraints limiting the purchase of supplies), price gouging likely significantly hinders residents. This can be addressed by:

- Encouraging reporting of price gouging activities

- Promoting the enforcement of anti-price gouging laws

- Educating consumers on the importance of recording violations and how to record them 
For issue \#2 (unconcern with well water quality contributing to unconcern with maintaining a sanitary system), better public education can address this lack of cognizance. Options for raising the public's understanding on this issue include:

- Enhance public health education

- Enhancing education on disinfection techniques for wells

- Enhance education on the importance of a sanitary well system

For issue \#3 (policies to promote local preparedness to last three days without regular water supply were inadequate), improvements could be made addressing the issue from two different angles. On one hand, residents can prepare for shortages lasting longer than three days. On the other hand, the counties can enhance their own ability to provide relief in a timelier manner, or to reduce the risk of shortages occurring. Options for improvement include:

- Water treatment methods can be made more widespread

- Enhance education

- Enhance infrastructure and power by increasing redundancy, storage capacity, structural integrity, backup power and structural stability

For issue \#4 (Younger people experienced more shortages that negatively affected their wellbeing potentially due to their preferred information sources), possible options include:

- Enhanced public health education

- Enhance knowledge by promoting younger residents being more involved with their community seniors and benefiting from their experience and primary information sources For issue \#5 (large proportion of people who received emergency relief did not actually need aid), the main improvement would be for: 
- Relief program efforts need to be more effective in reaching their targeted populations (those in desperate need of help)

\subsubsection{Step 6: Eliminate Poorer Options}

The best option for each issue was selected based on its accordance to the set criteria. Priority was placed on options adhering to higher ranked criteria. Options that were eliminated were not removed due to a lack of helpfulness, but to allow efforts to be focused on options that could have the greatest impact. Counties with limited resources can benefit from the refined list of options.

\subsubsection{Step 7: Choose Best Options (Recommendations for Improvement)}

The final list of options forms the list of potential improvements that are recommended for the counties in the study area. These improvements can help to promote better potable water management and avoid shortages in future hurricanes. The recommendations and the corresponding issues they address were as follows:

1) Issue \#1 (financial constraints limiting the purchase of supplies)

a. Promoting the enforcement of anti-price gouging laws. Stronger laws may also be pursued if needed. The other options (encourage reporting and educating consumers), while useful, are contingent on this improvement. They would accomplish little if the law itself was not enforced.

2) Issue \#2 (disregard with well water quality contributing to disregard with maintaining a sanitary system)

a. Enhancing education on the importance of a sanitary well system. The other options (Enhance public health education in general and enhancing education on well disinfection techniques), while useful, would not address the root of the issue 
well enough. General public health education would be broad and may not effectively build appreciation for keeping sanitary systems in time before the next severe storm. Enhancing education on well disinfection techniques would only be beneficial if the public were willing to learn and apply them to their private wells.

3) Issue \#3 (policies to promote local preparedness to last three days without regular water supply were inadequate).

a. Enhance infrastructure and power by increasing redundancy, storage capacity, structural integrity, backup power and structural stability. This would reduce the likelihood of water shortages caused by infrastructure or electrical failure from occurring. And/or...

b. Enhance education. Promote education that informs locals to prepare for water shortages that last longer than three days.

4) Issue \#4 (Younger people experienced more shortages that negatively affected their wellbeing potentially due to their preferred information sources)

a. Enhance knowledge by encouraging younger residents to be more involved with their community elders, thus benefiting from their experience and primary information sources. This option is focused and would promote the transfer of useful knowledge in dealing with severe storms to the younger generations. While generational gaps may hinder this increased community involvement, taking even the first constructive steps towards this end would still be valuable as it would lead to a positive outcome in the long-run.

5) Issue \#5 (large proportion of people who received emergency relief did not actually need aid) 
a. Relief program efforts should be made more effective in reaching their targeted populations. Encouraging people to only accept what they need can further help in this aspect. If residents who absolutely did not need relief received less to no aid, then there would be more resources available for those who were in crucial need. 


\section{CHAPTER EIGHT:}

\section{CONCLUSIONS}

Florida's beaches, humidity, and ample rains contribute to the general population's perception that the state has a plentiful supply of water. However, during times of crisis_like a severe hurricane-Floridians actually can experience potable water scarcity. The state of Florida frequently experiences hurricanes — sometimes many per year. These storms cause much damage and threaten the potable water supply.

A review of scholarly literature suggested that existing efforts in coping with hurricanecaused potable water paucity were insufficient. This thesis conducted a survey in the four counties of the study area which verified this fact. Completion of the research for this thesis has helped to indicate the state of potable water management efforts in the selected counties. The issues found in this study should be resolved to protect people's wellbeing in future storms. Towards this end, this study has also used a rational decision-making model to make several recommendations (including focusing relief program efforts more efficiently and strengthening/enforcing price gouging laws) to address problems in potable water preparation and emergency response. These recommendations would benefit the residents of Miami-Dade, Collier, Lee, and Hillsborough counties by helping them cope with and potentially avoid the drinking water impacts of severe storms. 
This research may help county officials and contingency planners by focusing their efforts on issues where the most stands to be achieved. Better potable water management in the future would thus be facilitated along with improved resiliency of potable water supplies.

Financial limitations affected this study's linguistic and spatial scope. Distributing the survey across more than four counties would have increased the research cost beyond what the budget allowed. Furthermore, translating the survey to other languages would have entailed additional fees. The survey dissemination was also limited to people who had internet access. Respondents had to have a Wi-Fi enabled device (such as a cell phone, laptop, computer, tablet, etc.) and access to an internet network. Another limitation involved potential recall bias. Since Hurricane Irma occurred in 2017, and the survey was distributed the following year, some respondents may not have been able to exactly remember their experiences regarding potable water during the storm.

Future research may expand on this study by considering a larger study area (such as different counties or the entire state of Florida). Future research may also consider other languages besides English so as to be more inclusive of non-English speaking people. The survey in this study may be disseminated again for a future storm in order to glean any changes in preparations and responses over time. Furthermore, wells can be tested in the study area after hurricanes to determine whether or not contamination occurred. Future research can also investigate the equity of emergency relief supply distribution in greater depth. Additionally, with regard to resilience, this study was concerned with return to the "original state" of pre-disaster conditions since this would obviously be better than conditions directly after landfall. Future studies may explore the "original state" during non-disaster conditions to improve people's access to potable water under non-emergency situations as well. 


\section{REFERENCES}

Abrams, L. (2003). Capacity Building for Water Supply and Sanitation Development at Local Level: The Threshold Concept. In The Water Page. Retrieved July 30, 2018, from http://www.africanwater.org/capacity_building.htm

Bae, E. (2009). Are Anti-Price Gouging Legislations Effective Against Sellers During

Disasters?. Entrepreneurial Business Law Journal, 4, 79-100.

Baker, E. J. (2011). Household Preparedness for the Aftermath of Hurricanes in Florida. Applied Geography, 31, 46-52.

Bayleyegn, T., Wolkin, A., Oberst, K., Young, S., Sanchez, C., Phelps, A., Schulte, J., Rubin, C., \& Batts, D. (2006). Rapid Assessment of the Needs and Health Status in Santa Rosa and Escambia Counties, Florida, After Hurricane Ivan, September 2004. Disaster Management \& Response, 4, 12-18.

Bilskie, M. V., \& Hagen, S. C. (2018). Defining Flood Zone Transitions in Low-Gradient Coastal Regions. Geophysical Research Letters, 45, 2761-2770.

Bostrom, A., Morss, R., Lazo, J. K., Demuth, J., \& Lazrus, H. (2018, February). Eyeing the Storm: How Residents of Coastal Florida See Hurricane Forecasts and Warnings. International Journal of Disaster Risk Reduction, 1-15. 
Carpenter, S., Walker, B., Anderies, J. M., \& Abel, N. (2001). From Metaphor to Measurement: Resilience of What to What?. Ecosystems, 4, 765-781.

Carroll, A. E., \& Frakt, A. B. (2017). Children's Health Must Remain a Focus in the Recovery From Hurricane Harvey. Jama Pediatrics, 171, 1029-1030.

Chatterjee, C., \& Mozumder, P. (2015). Hurricane Wilma, Utility Disruption, and Household Wellbeing. International Journal of Disaster Risk Reduction, 14, 395-402.

Collier County. (2018). Emergency Management. Retrieved October 5, 2018, from https://www.colliercountyfl.gov/your-government/divisions-a-e/emergency-management

Collins, J., Ersing, R., Polen, A., Saunders, M., \& Senkbeil, J. (2018). The Effects of Social Connections on Evacuation Decision Making During Hurricane Irma. Weather, Climate, and Society, 10, 459-469.

Creative Research Systems. (2012). Sample Size Calculator. Retrieved October 15, 2018, from https://www.surveysystem.com/sscalc.htm

Cumming, G. S. (2011). Spatial Resilience: Integrating Landscape Ecology, Resilience, and Sustainability. Landscape Ecology, 26, 899-909.

Desouza, K. C., \& Flanery, T. H. (2013). Designing, Planning, and Managing Resilient Cities: A Conceptual Framework. Cities, 35, 89-99. 
Exum, N. G., Betanzo, E., Schwab, K. J., Chen, T. Y. J., Guikema, S., \& Harvey, D. E. (2018).

Extreme Precipitation, Public Health Emergencies, and Safe Drinking Water in the USA. Current Environmental Health Reports, 5, 305-315.

FEMA. (2017). Hurricane Maria Response and Relief Operations Underway. Retrieved April 23, 2018, https://www.fema.gov/news-release/2017/09/21/hurricane-maria-responseand-relief-operations-underway

Fierro, A. O., Stevenson, S. N., \& Rabin, R. M. (2018). Evolution of GLM-Observed Total Lightning in Hurricane Maria (2017) During the Period of Maximum Intensity. Monthly Weather Review, 146, 1641-1666.

FloridaDemographicsbyCubit. (2017). Florida Counties by Population. Retrieved June 9, 2018, from https://www.florida-demographics.com/counties_by_population

Florida Department of Health. (2017). Risks to Water Supply Due to Hurricane Irma. Retrieved April 12, 2018, from http://collier.floridahealth.gov/newsroom/2017/09/0907riskstowatersupply.html

Florida Disaster Division of Emergency Management. (2018). Irma Recovery. Retrieved April 11, 2018, from https://www.floridadisaster.org/info/irma-recovery/ Folke, C. (2006). Resilience: The Emergence of a Perspective for Social-Ecological Systems Analyses. Global Environmental Change, 16, 253-267. 
Garcia-Lopez, G. A. (2018). The Multiple Layers of Environmental Injustice in Contexts of (Un)natural Disasters: The Case of Puerto Rico Post-Hurricane Maria. Environmental Justice, 11, 101-108.

Hillsborough County. (2018). Emergency Management. Retrieved October 4, 2018, from http://www.hillsboroughcounty.org/en/residents/public-safety/emergencymanagement/stay-safe

Kapoor, V., Gupta, I., Pasha, A. B. M. T., \& Phan, D. (2018). Real-Time Quantitative PCR Measurements of Fecal Indicator Bacteria and Human-Associated Source Tracking Markers in a Texas River Following Hurricane Harvey. Environmental Science \& Technology Letters, 5, 322-328.

Khan, S. J., Deere, D., Leusch, F. D. L., Humpage, A., Jenkins, M., \& Cunliffe, D. (2015).

Extreme Weather Events: Should Drinking Water Quality Management Systems Adapt to Changing Risk Profiles?. Water Research, 85, 124-136.

Krumboltz, J. D., Scherba, D. S., Hamel, D. A., \& Mitchell, L. K. (1982). Effect of Training in Rational Decision Making on the Quality of Simulated Career Decisions. Journal of Counseling Psychology, 29, 618-625.

Lee County Southwest Florida. (2018). Hurricane Preparation Guide. Retrieved October 5, 2018, from http://www.leegov.com/hurricane 
MacMillan, D. (2017). In Irma, Emergency Responders' New Tools: Twitter and Facebook. In The Wall Street Journal. Retrieved March 21, 2019, from https://www.wsj.com/articles/for-hurricane-irma-information-officials-post-on-socialmedia-1505149661

MapWise. (2018). Florida Counties Map. Retrieved June 10, 2018, from https://www.mapwise.com/maps/florida/florida-counties-map.php

Matthews, J. C. (2015). Disaster Resilience of Critical Water Infrastructure Systems. Journal of Structural Engineering, 142, 1-4.

Meerow, S., Newell, J. P., \& Stults, M. (2016). Defining urban resilience: A review. Landscape and Urban Planning, 147, 38-49.

Miami-Dade County. (2018). Official Hurricane Readiness Guide. Retrieved October 5, 2018, from https://www8.miamidade.gov/main/hurricane.page

National Weather Service. (2017). Hurricane Irma Local Report/Summary. Retrieved March 21, 2019, from https://www.weather.gov/mfl/hurricaneirma

Qualtrics. (2018). Sample Size Calculator. Retrieved October 15, 2018, from https://www.qualtrics.com/blog/calculating-sample-size/ 
Ram, P. K., Blanton, E., Klinghoffer, D., Platek, M., Piper, J., Straif-Bourgeois, S., Bonner, M. R., \& Mintz, E. D. (2006). Household Water Disinfection in Hurricane-Affected Communities of Louisiana: Implications for Disaster Preparedness for the General Public. American Journal of Public Health, 97, 130-135.

Ruecker, A., Uzun, H., Karanfil, T., Tsui, M. T. K., \& Chow, A. T. (2017). Disinfection Byproduct Precursor Dynamics and Water Treatability During an Extreme Flooding Event in a Coastal Blackwater River in Southeastern United States. Chemosphere, 188, 90-98.

Schroeder, A. (2017). Who's Most Vulnerable to Hurricane Irma? Those Vulnerable the Day Before. In Direct Relief. Retrieved June 9, 2018, from https://www.directrelief.org/2017/09/whos-most-vulnerable-to-hurricane-irma-thosevulnerable-the-day-before/

Senkbeil, J., Collins, J., \& Reed, J. (2019). Evacuee Perception of Geophysical Hazards for Hurricane Irma. Weather, Climate, and Society, 11, 217-227.

Sharifi, A., \& Yamagata, Y. (2014). Resilient Urban Planning: Major Principles and Criteria. Energy Procedia, 61, 1491-1495.

Shuckburgh, E., Mitchell, D., \& Stott, P. (2017). Hurricanes Harvey, Irma and Maria: How Natural Were These 'Natural Disasters?'. Weather, 72, 353-354. 
Smith, B. (2017). Hurricane Irma Damage Toll in Lee County: $\$ 742$ Million and Rising. In News-Press. Retrieved March 21, 2019, from https://www.newspress.com/story/news/2017/09/29/hurricane-irma-damage-toll-lee-county-742-millionand-rising/716192001/

Statistical Methods. (2018). Sample Size Determination. Retrieved October 15, 2018, from https://statistical-methods.com/sample-size-determination/

SunSentinel. (2017). Florida Has Settled Just One Hurricane Irma Price-Gouging Case.

Retrieved July 31, 2018, from http://www.sun-sentinel.com/news/florida/fl-reghurricane-irma-price-gouging-20171213-story.html

SurveyMonkey. (2018). Sample Size Calculator. Retrieved October 15, 2018, from https://www.surveymonkey.com/mp/sample-size-calculator/

Taylor, L. (2017). Hillsborough Spared Widespread Damage from Hurricane Irma. In Tampa Bay Times. Retrieved March 21, 2019, from https://www.tampabay.com/news/weather/hurricanes/hillsborough-spared-widespreaddamage-from-hurricane-irma/2337039

TCPalm. (2017). Price-Gouging Complaints During Hurricane Irma Top 14,000 In Florida. Retrieved October 4, 2018, from https://www.tcpalm.com/story/weather/hurricanes/2017/10/11/price-gouging-complaintsduring-hurricane-irma-top-14-000-florida/750312001/ 
Thatcher, A., Wretschko, G., \& Fridjhon, P. (2008). Online Flow Experiences, Problematic Internet Use and Internet Procrastination. Computers in Human Behavior, 24, 2236-2254.

Torres, H. \& Alsharif, K. (2016). Reflecting on Resilience in Broward County, Florida: A Newspaper Content Analysis About Hurricane Wilma Recovery. International Journal of Disaster Risk Reduction, 19, 36-46.

Torres, H. \& Alsharif, K. (2017). What it Means to Become "More Resilient": An Analysis of Local Resilience-Building Approaches in Three Florida Communities. Weather, Climate, and Society, 9, 405-419.

Torres, H. R., Alsharif, K. A., \& Tobin, G. A. (2018). Perspectives on Adaptive Capacity to Climate Change in Hazardous Environments: Insights from Broward County, Florida. Weather, Climate, and Society, 10, 361-372.

United States Census Bureau. (2017). QuickFacts Florida. Retrieved August 3, 2018, from https://www.census.gov/quickfacts/fl

Wilkinson, C. (2011). Social-Ecological Resilience: Insights and Issues for Planning Theory. Planning Theory, 11, 148-169.

Zhang, X., \& Li, H. (2018). Urban Resilience and Urban Sustainability: What We Know and What Do Not Know?. Cities, 72, 141-148. 


\section{APPENDIX A: \\ WATER SCARCITY IN THE FACE OF HURRICANES QUESTIONNAIRE}

This survey is part of graduate research for a Master's Thesis at the University of South Florida. It aims to gain a better understanding of the negative impacts of Hurricane Irma. Specifically, this questionnaire will be used to collect data on the impacts the hurricane had on drinking water supplies in Florida. Please respond to the best of your ability as the results of this research will aid in improving preparation and emergency response to hurricanes in your county.

1) At the time of Hurricane Irma, where was your primary residence?
a. Miami-Dade County
b. Collier County
c. Lee County
d. Hillsborough County
e. None of the above

2) Did you evacuate from your primary residence in anticipation of Hurricane Irma? Note: If your primary residence was not in Florida, please select (e).
a. Yes (out of state)
b. Yes (in-state shelter)
c. Yes (in-state other)
d. No (did not evacuate)
e. N/A (primary residence was not in Florida at the time of Hurricane Irma) 
3) Please indicate all drinking water preparations that you undertook for Hurricane Irma.
a. Stocked bottled water
b. Stocked ice
c. Stocked bathtub with water
d. Stocked containers with water
e. Stocked swimming pool
f. Other (please specify)

4) Which of the following applies to the primary drinking water source of your home?
a. Municipal water supply
b. Well water
c. Bottled water
d. Other (please specify)

5) Please indicate all of the water treatment methods that you employed at the time of Hurricane Irma.
a. Chlorine disinfection
b. Iodine disinfection
c. Boiling
d. Disinfection tablets
e. Other (please specify) 
6) During Hurricane Irma, did you run out of traditional drinking water? (Here, "traditional" refers to water that is ready to drink with no treatment needed.)
a. Yes
b. No

7) During Hurricane Irma, did you run out of bottled water?
a. Yes
b. No
c. Did not have bottled water

8) During Hurricane Irma, did your home run out of drinking water from municipal supply?
a. Yes
b. No
c. Did not have municipal supply

9) During Hurricane Irma, did you run out of drinking water from your private well? (via contamination, etc.)
a. Yes
b. No
c. Did not have a well

10) During Hurricane Irma, did lack of drinking water negatively impact your wellbeing? (Negative impacts may include physical health concerns, anxiety, stress, etc.)
a. Yes
b. No 
11) Please indicate all issues regarding drinking water that negatively affected you at the time of Hurricane Irma. (In other words, which of these caused you to obtain less drinking water than you needed?)
a. Price gouging (example: stores charged higher prices for water)
b. Damaged infrastructure (example: damaged pipes)
c. Lack of emergency relief
d. Other (please specify
e. N/A

12) Approximately how long did it take for you to re-obtain reliable access to traditional drinking water? (Here, "reliable access" refers to continuous supply with no disruption.)

a. (please indicate a time period with units. For example: 3 days)

13) Approximately how long did it take for you to re-obtain reliable access to bottled water?

a. (please indicate a time period with units. For example: 3 days)

14) Approximately how long did it take for your home to re-obtain drinking water from municipal supply?
a. (please indicate a time period with units. For example: 3 days)
b. N/A 
15) Approximately how long did it take for you to re-obtain drinking water from your private well?
a. (please indicate a time period with units. For example: 3 days)
b. N/A

16) At the time of Hurricane Irma, which of the following would have best described you? (Here, "experienced" means having lived through a past hurricane)
a. I had not experienced previous hurricanes prior to Hurricane Irma
b. Hurricane Irma was the first hurricane I experienced in Florida
c. I had experienced previous hurricanes in Florida before Hurricane Irma

17) Please indicate which response best represents your answer to the statement: "By landfall, I felt well-prepared for Hurricane Irma with regard to drinking water." a. Strongly Disagree---Disagree---Neutral---Agree---Strongly Agree

18) Please indicate which response best represents your answer to the statement: "After landfall, all my preparations were sufficient in meeting my drinking water needs to last 3 days at least."

a. Strongly Disagree---Disagree---Neutral---Agree---Strongly Agree 
19) What was your primary source of information regarding the status of traditional drinking water quality?
a. TV
b. Radio
c. Social media
d. Internet
e. Word of mouth
f. Other (please specify)

20) What was your primary source of information regarding water treatment methods?
a. TV
b. Radio
c. Social media
d. Internet
e. Word of mouth
f. Other (please specify)

21) Please indicate the level of your agreement to the following statement: "I feel that stores where I live(d) during Hurricane Irma were adequately stocked with drinking water during the event."
a. Strongly Disagree---Disagree---Neutral---Agree---Strongly Agree

22) Please indicate the level of your agreement to the following statement: "During Hurricane Irma, I felt confident in my ability to apply chlorine disinfection for water treatment."

a. Strongly Disagree---Disagree---Neutral---Agree---Strongly Agree 
23) Please indicate the level of your agreement to the following statement: "During Hurricane Irma, I felt confident in my ability to disinfect my well."

a. Strongly Disagree---Disagree---Neutral---Agree---Strongly Agree

24) Please indicate the level of your agreement to the following statement: "During Hurricane Irma, I felt confident in my ability to boil water for drinking water."
a. Strongly Disagree---Disagree---Neutral---Agree---Strongly Agree

25) Did you receive drinking water from relief supplies? Please indicate all that apply.
a. Yes (City relief)
b. Yes (County relief)
c. Yes (State relief)
d. Yes (Federal relief)
e. Yes (Other) Please specify:
f. Yes (but unsure of source)
g. No

26) How satisfied were you with the level of aid you received from these sources?

a. City

i. Strongly Dissatisfied---Dissatisfied---Neutral---Satisfied---Strongly Satisfied

ii. N/A

b. County

i. Strongly Dissatisfied---Dissatisfied---Neutral---Satisfied---Strongly Satisfied

ii. N/A 
c. State

i. Strongly Dissatisfied---Dissatisfied---Neutral---Satisfied---Strongly Satisfied

ii. N/A

d. Federal

i. Strongly Dissatisfied---Dissatisfied---Neutral---Satisfied---Strongly Satisfied

ii. N/A

27) Were you in absolute need of drinking water from relief supplies?
a. Yes
b. No

Please choose the options that would have best described you at the time of

\section{Hurricane Irma.}

\section{8) Gender?}
a. Male
b. Female

29) Age?
a. 24 or less
b. $25-34$
c. $35-44$
d. 45-54
e. $55-64$
f. 65 or more 


\section{0) Education Level?}
a. Elementary School
b. High school
c. College (undergraduate level)
d. College (graduate level)

\section{1) Ethnicity?}
a. Asian
b. Black
c. Caucasian
d. Hispanic
e. Native American
f. Other

\section{2) Income?}
a. $<\$ 30,000$ per year
b. $\$ 30,000-\$ 100,000$ per year
c. $>\$ 100,000$ per year

\section{3) Household Size (number of people)?}
a. 1
b. 2
c. 3
d. 4 or more 
34) Were there any other drinking water problems that you experienced during Hurricane Irma?

a. 


\section{APPENDIX B:}

\section{IRB APPROVAL LETTER}

The following is the approval letter received from the USF Institutional Review Board. Obtaining this approval was a requirement in order to distribute the survey for this study. 
TOS

UNIVERSITY OF

SOUTH FLORIDA

November 13, 2018

Fautemeh Sajadi Bami

School of Geosciences

Tampa, FL 33612

\section{RE: Exempt Certification}

IRB\#: Pro00037766

Title: Water Scarcity in the Face of Hurricanes: Improving the Resilience of Potable Water Supplies in Selected Florida Counties

Dear Ms. Sajadi Bami:

On 11/11/2018, the Institutional Review Board (IRB) determined that your research meets criteria for exemption from the federal regulations as outlined by 45CFR46.101(b):

(2) Research involving the use of educational tests (cognitive, diagnostic, aptitude, achievement), survey procedures, interview procedures or observation of public behavior, unless:

(i) information obtained is recorded in such a manner that human subjects can be identified, directly or through identifiers linked to the subjects; and (ii) any disclosure of the human subjects' responses outside the research could reasonably place the subjects at risk of criminal or civil liability or be damaging to the subjects' financial standing, employability, or reputation.

As the principal investigator for this study, it is your responsibility to ensure that this research is conducted as outlined in your application and consistent with the ethical principles outlined in the Belmont Report and with USF HRPP policies and procedures.

Please note, as per USF HRPP Policy, once the Exempt determination is made, the application is closed in ARC. Any proposed or anticipated changes to the study design that was previously declared exempt from IRB review must be submitted to the IRB as a new study prior to initiation of the change. However, administrative changes, including changes in research personnel, do not warrant an amendment or new application.

Given the determination of exemption, this application is being closed in ARC. This does not limit your ability to conduct your research project.

We appreciate your dedication to the ethical conduct of human subject research at the University of South Florida and your continued commitment to human research protections. If you have any questions regarding this matter, please call 813-974-5638.

Sincerely,

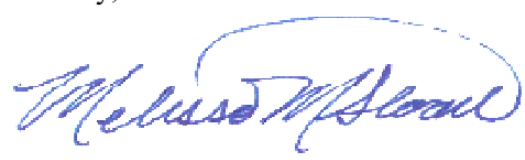

Melissa Sloan, $\mathrm{PhD}$, Vice Chairperson

USF Institutional Review Board 
APPENDIX C:

\section{FAIR USE WORKSHEETS}

The following are Fair Use Worksheets detailing why the use of information from published journal articles is permitted for this thesis. 


\section{Baker (2011) Household Preparedness for the Aftermath of Hurricanes in Florida:}

University of South Florida

\section{USF Fair Use Worksheet}

The fair use exception was added to the Copyright Act of 1976 as section 107 and was based on a history of judicial decisions that recognized that unauthorized use of copyrighted materials were "fair uses." The distinction between fair use and infringement may be unclear and not easily defined. There is no specific number of words, lines, or notes that may safely be taken without permission. This worksheet is offered as a tool to help you determine if your use of copyrighted content is likely to be considered to be a "fair use."

Before you begin your fair use determination, ask yourself the following questions:

1. Is the work no longer protected by copyright?

a. Is it in the public domain?

b. Did I retain my copyright ownership over a work I created when signing my publication contract?

2. Is there a specific exception in copyright law that covers my use?

a. Does my use fit within Section 108 of copyright law: 'Reproduction by libraries and archives?'

b. Does my use fit within Section 110 (1) of copyright law: 'performance or display of works in face to face classrooms?'

c. Does my use fit within Section 110 (2) of copyright law: 'performance or display of works in online classrooms (also known as the TEACH Act)?' see TEACH Act checklist

3. Is there a license that covers my use?

a. Is the work issued under a Creative Commons license and can I comply with the license terms?

b. Do I have access to the material through library licensed content? Ask your librarian

If your answer to the above questions was no, then you should proceed with your fair use evaluation. Section 107 also sets out four factors to be considered in determining whether or not a particular use is fair:

1. The purpose and character of the use, including whether such use is of commercial nature or is for nonprofit educational purposes

2. The nature of the copyrighted work

3. The amount and substantiality of the portion used in relation to the copyrighted work as a whole

4. The effect of the use upon the potential market for, or value of, the copyrighted work

None of these factors are independently determinative of whether or not a use is likely to be considered fair use. In evaluating your use, you should evaluate the totality of the circumstances and consider all of the factors together. The Fair Use Worksheet will help you balance these factors to determine if your use of copyrighted material weighs in favor of 'fair use.' While valuable for your own documentation the Worksheet is not intended as legal advice, which can be provided only by USF General Counsel.

LeEtta Schmidt, Imschmidt@usf.edu and Drew Smith dsmith@usf.edu Reviewed by USF General Counsel 08/11/2015 


\section{INSTRUCTIONS}

Check all boxes that apply, and keep a copy of this form for your records. If you have questions, please contact the USF General Counsel or your USF Tampa Library Copyright Librarian.

Name: Fautemeh Sajadi Bami Date: Feb 28, 2019

Class or Project: Master's Thesis

Title of Copyrighted Work:

PURPOSE AND CHARACTER OF THE USE

\begin{tabular}{|l|l|}
\hline Likely Supports Fair Use & Likely Does Not Support Fair Use \\
\hline$\square$ Educational & $\square$ Commercial \\
$\square$ Teaching (including multiple copies for & $\square$ Entertainment \\
classroom use) & $\square$ Bad-faith behavior \\
$\square$ Research or Scholarship & $\square$ Denying credit to original author \\
$\square$ Criticism, Parody, News Reporting or & $\square$ Non-transformative or exact copy \\
Comment & $\square$ Made accessible on Web or to public \\
$\square$ Transformative Use (your new work relies on & $\square$ Profit-generating use \\
and adds new expression, meaning, or message & \\
to the original work) & \\
$\square$ Restricted Access (to students or other & \\
appropriate group) & \\
$\square$ Nonprofit & \\
\end{tabular}

Overall, the purpose and character of your use $\boxminus$ supports fair use or $\square$ does not support fair use.

NATURE OF THE COPYRIGHTED MATERIAL

\begin{tabular}{|l|l|}
\hline Likely Supports Fair Use & Likely Does Not Support Fair Use \\
\hline Factual or nonfiction & $\square$ Creative or fiction \\
Important to favored educational objectives & $\square$ Consumable (workbooks, tests) \\
■ Published work & $\square$ Unpublished \\
\hline
\end{tabular}

Overall, the nature of the copyrighted material $\square$ supports fair use or $\square$ does not support fair use.

AMOUNT AND SUBSTANTIALITY OF MATERIAL USED IN RELATION TO WHOLE

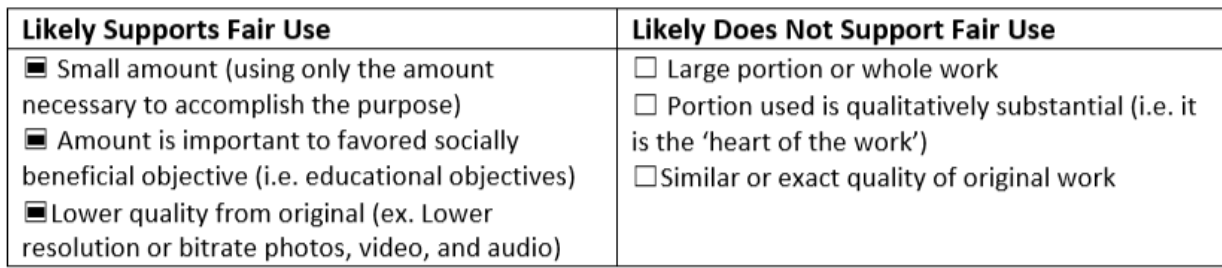

LeEtta Schmidt, Imschmidt@usf.edu and Drew Smith dsmith@usf.edu Reviewed by USF General Counsel 08/11/2015 
Overall, the amount and substantiality of material used in relation to the whole $\boldsymbol{E}_{\text {supports fair use or }}$ $\square$ does not support fair use.

\section{EFFECT ON THE MARKET FOR ORIGINAL}

\begin{tabular}{|l|l|}
\hline Likely Supports Fair Use & Likely Does Not Support Fair Use \\
\hline 口 No significant effect on the market or & $\square$ Replaces sale of copyrighted work \\
potential market for the original & $\square$ Significantly impairs market or potential \\
$\square$ No similar product marketed by the copyright & market for the work \\
holder & $\square$ Numerous copies or repeated, long-term use \\
$\square$ You own a lawfully acquired copy of the & $\square$ Made accessible on Web or to public \\
material & $\square$ Affordable and reasonably available \\
$\square$ The copyright holder is unidentifiable & permissions or licensing \\
$\square$ Lack of licensing mechanism for the material & \\
\hline
\end{tabular}

Overall, the effect on the market for the original $\square$ supports fair use or $\square$ does not support fair use.

\section{CONCLUSION}

The combined purpose and character of the use, nature of the copyrighted material, amount and substantiality of material used in relation to the whole and the effect on the market for the original

Đlikely supports fair use or $\square$ likely does not support fair use.

Note: Should your use of copyrighted material not support fair use, you may still be able to locate and request permissions from the copyright holder. For help on this, please feel free to contact your Copyright Librarian.

This worksheet has been adapted from:

Cornell University's Checklist for Conducting A Fair use Analysis Before Using Copyrighted Materials: https://copyright.cornell.edu/policies/docs/Fair Use Checklist.pdf

Crews, Kenneth D. (2008) Fair use Checklist. Columbia University Libraries Copyright Advisory Office. http://copyright.columbia.edu/copyright/files/2009/10/fairusechecklist.pdf

Smith, Kevin; Macklin, Lisa A.; Gilliland, Anne. A Framework for Analyzing any Copyright Problem. Retrieved from: https://d396qusza40orc.cloudfront.net/cfel/Readina\%20Docs/A\%20Framework\%20for\%20Analyzina\%20a ny\%20Copyright\%20Problem.pdf

LeEtta Schmidt, Imschmidt@usf.edu and Drew Smith dsmith@usf.edu Reviewed by USF General Counsel 08/11/2015 
Khan et al. (2015) Extreme Weather Events: Should Drinking Water Quality Management Systems Adapt to Changing Risk Profiles?:

University of South Florida

\section{INSTRUCTIONS}

Check all boxes that apply, and keep a copy of this form for your records. If you have questions, please contact the USF General Counsel or your USF Tampa Library Copyright Librarian.

Name: Fautemeh Sajadi Bami Date: March 1, 2019

Class or Project: Master's Thesis Title of Copyrighted Work: Extreme Weather Events: Should Drinkir PURPOSE AND CHARACTER OF THE USE

\begin{tabular}{|l|l|}
\hline Likely Supports Fair Use & Likely Does Not Support Fair Use \\
\hline E Educational & $\square$ Commercial \\
$\square$ Teaching (including multiple copies for & $\square$ Entertainment \\
classroom use) & $\square$ Bad-faith behavior \\
$\square$ Research or Scholarship & $\square$ Denying credit to original author \\
$\square$ Criticism, Parody, News Reporting or & $\square$ Non-transformative or exact copy \\
Comment & $\square$ Made accessible on Web or to public \\
G Transformative Use (your new work relies on & $\square$ Profit-generating use \\
and adds new expression, meaning, or message & \\
to the original work) & \\
$\square$ Restricted Access (to students or other & \\
appropriate group) & \\
$\square$ Nonprofit & \\
\hline
\end{tabular}

NATURE OF THE COPYRIGHTED MATERIAL

\begin{tabular}{|l|l|}
\hline Likely Supports Fair Use & Likely Does Not Support Fair Use \\
\hline E Factual or nonfiction & $\square$ Creative or fiction \\
E Important to favored educational objectives & $\square$ Consumable (workbooks, tests) \\
Published work & $\square$ Unpublished \\
\hline
\end{tabular}

Overall, the nature of the copyrighted material $\square$ supports fair use or $\square$ does not support fair use.

AMOUNT AND SUBSTANTIALITY OF MATERIAL USED IN RELATION TO WHOLE

\begin{tabular}{|l|l|}
\hline Likely Supports Fair Use & Likely Does Not Support Fair Use \\
\hline 口 Small amount (using only the amount & $\square$ Large portion or whole work \\
necessary to accomplish the purpose) & $\square$ Portion used is qualitatively substantial (i.e. it \\
E Amount is important to favored socially & is the 'heart of the work') \\
beneficial objective (i.e. educational objectives) & $\square$ Similar or exact quality of original work \\
ELower quality from original (ex. Lower & \\
resolution or bitrate photos, video, and audio) & \\
\hline
\end{tabular}

LeEtta Schmidt, Imschmidt@usf.edu and Drew Smith dsmith@usf.edu Reviewed by USF General Counsel 08/11/2015 
Overall, the amount and substantiality of material used in relation to the whole $\square$ supports fair use or $\square$ does not support fair use.

\section{EFFECT ON THE MARKET FOR ORIGINAL}

\begin{tabular}{|l|l|}
\hline Likely Supports Fair Use & Likely Does Not Support Fair Use \\
\hline$\square$ No significant effect on the market or & $\square$ Replaces sale of copyrighted work \\
potential market for the original & $\square$ Significantly impairs market or potential \\
$\square$ No similar product marketed by the copyright & market for the work \\
holder & $\square$ Numerous copies or repeated, long-term use \\
$\square$ You own a lawfully acquired copy of the & $\square$ Made accessible on Web or to public \\
material & $\square$ Affordable and reasonably available \\
$\square$ The copyright holder is unidentifiable & permissions or licensing \\
$\square$ Lack of licensing mechanism for the material & \\
\hline
\end{tabular}

Overall, the effect on the market for the original $\square$ supports fair use or $\square$ does not support fair use.

\section{CONCLUSION}

The combined purpose and character of the use, nature of the copyrighted material, amount and substantiality of material used in relation to the whole and the effect on the market for the original

\section{$\square$ likely supports fair use or $\square$ likely does not support fair use.}

Note: Should your use of copyrighted material not support fair use, you may still be able to locate and request permissions from the copyright holder. For help on this, please feel free to contact your Copyright Librarian.

This worksheet has been adapted from:

Cornell University's Checklist for Conducting A Fair use Analysis Before Using Copyrighted Materials: https://copyright.cornell.edu/policies/docs/Fair Use Checklist.pdf

Crews, Kenneth D. (2008) Fair use Checklist. Columbia University Libraries Copyright Advisory Office. http://copyright.columbia.edu/copyright/files/2009/10/fairusechecklist.pdf

Smith, Kevin; Macklin, Lisa A.; Gilliland, Anne. A Framework for Analyzing any Copyright Problem. Retrieved from: https://d396qusza40orc.cloudfront.net/cfel/Readina\%20Docs/A\%20Framework\%20for\%20Analyzina\%20a ny\%20Copyright\%20Problem.pdf

LeEtta Schmidt, Imschmidt@usf.edu and Drew Smith dsmith@usf.edu Reviewed by USF General Counsel 08/11/2015 
Schroeder (2017) Who's Most Vulnerable to Hurricane Irma? Those Vulnerable the Day

Before:

University of South Florida

\section{INSTRUCTIONS}

Check all boxes that apply, and keep a copy of this form for your records. If you have questions, please contact the USF General Counsel or your USF Tampa Library Copyright Librarian.

Name: Fautemeh Sajadi Bami Date: March 1, 2019

Class or Project: Master's Thesis

Title of Copyrighted Work:

Who's Most Vulnerable to Hurricane Irn

PURPOSE AND CHARACTER OF THE USE

\begin{tabular}{|l|l|}
\hline Likely Supports Fair Use & Likely Does Not Support Fair Use \\
\hline E Educational & $\square$ Commercial \\
$\square$ Teaching (including multiple copies for & $\square$ Entertainment \\
classroom use) & $\square$ Bad-faith behavior \\
$\square$ Research or Scholarship & $\square$ Denying credit to original author \\
$\square$ Criticism, Parody, News Reporting or & $\square$ Non-transformative or exact copy \\
Comment & $\square$ Made accessible on Web or to public \\
日 Transformative Use (your new work relies on & $\square$ Profit-generating use \\
and adds new expression, meaning, or message & \\
to the original work) & \\
$\square$ Restricted Access (to students or other & \\
appropriate group) & \\
$\square$ Nonprofit & \\
\hline
\end{tabular}

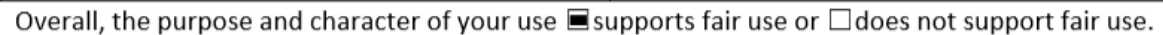

NATURE OF THE COPYRIGHTED MATERIAL

\begin{tabular}{|l|l|}
\hline Likely Supports Fair Use & Likely Does Not Support Fair Use \\
\hline E Factual or nonfiction & $\square$ Creative or fiction \\
Important to favored educational objectives & $\square$ Consumable (workbooks, tests) \\
Published work & $\square$ Unpublished \\
\hline
\end{tabular}

Overall, the nature of the copyrighted material ㅍsupports fair use or $\square$ does not support fair use.

AMOUNT AND SUBSTANTIALITY OF MATERIAL USED IN RELATION TO WHOLE

\begin{tabular}{|c|c|}
\hline Likely Supports Fair Use & Likely Does Not Support Fair Use \\
\hline $\begin{array}{l}\text { E Small amount (using only the amount } \\
\text { necessary to accomplish the purpose) } \\
\text { Amount is important to favored socially } \\
\text { beneficial objective (i.e. educational objectives) } \\
\text { ELower quality from original (ex. Lower } \\
\text { resolution or bitrate photos, video, and audio) }\end{array}$ & $\begin{array}{l}\square \text { Large portion or whole work } \\
\square \text { Portion used is qualitatively substantial (i.e. it } \\
\text { is the 'heart of the work') } \\
\square \text { Similar or exact quality of original work }\end{array}$ \\
\hline
\end{tabular}

LeEtta Schmidt, Imschmidt@usf.edu and Drew Smith dsmith@usf.edu Reviewed by USF General Counsel 08/11/2015 
Overall, the amount and substantiality of material used in relation to the whole $\square_{\text {supports fair use or }}$ $\square$ does not support fair use.

\section{EFFECT ON THE MARKET FOR ORIGINAL}

\begin{tabular}{|l|l|}
\hline Likely Supports Fair Use & Likely Does Not Support Fair Use \\
\hline$\square$ No significant effect on the market or & $\square$ Replaces sale of copyrighted work \\
potential market for the original & $\square$ Significantly impairs market or potential \\
$\square$ No similar product marketed by the copyright & market for the work \\
holder & $\square$ Numerous copies or repeated, long-term use \\
$\square$ You own a lawfully acquired copy of the & $\square$ Made accessible on Web or to public \\
material & $\square$ Affordable and reasonably available \\
$\square$ The copyright holder is unidentifiable & permissions or licensing \\
$\square$ Lack of licensing mechanism for the material & \\
\hline
\end{tabular}

Overall, the effect on the market for the original $\square$ supports fair use or $\square$ does not support fair use.

\section{CONCLUSION}

The combined purpose and character of the use, nature of the copyrighted material, amount and substantiality of material used in relation to the whole and the effect on the market for the original

छlikely supports fair use or $\square$ likely does not support fair use.

Note: Should your use of copyrighted material not support fair use, you may still be able to locate and request permissions from the copyright holder. For help on this, please feel free to contact your Copyright Librarian.

This worksheet has been adapted from:

Cornell University's Checklist for Conducting A Fair use Analysis Before Using Copyrighted Materials: https://copyright.cornell.edu/policies/docs/Fair Use Checklist.pdf

Crews, Kenneth D. (2008) Fair use Checklist. Columbia University Libraries Copyright Advisory Office. http://copyright.columbia.edu/copyright/files/2009/10/fairusechecklist.pdf

Smith, Kevin; Macklin, Lisa A.; Gilliland, Anne. A Framework for Analyzing any Copyright Problem. Retrieved from: https://d396qusza40orc.cloudfront.net/cfel/Readina\%20Docs/A\%20Framework\%20for\%20Analyzina\%20a ny\%20Copyright\%20Problem.pdf

LeEtta Schmidt, Imschmidt@usf.edu and Drew Smith dsmith@usf.edu Reviewed by USF General Counsel 08/11/2015 


\section{MapWise (2018) Florida Counties Map:}

University of South Florida

\section{INSTRUCTIONS}

Check all boxes that apply, and keep a copy of this form for your records. If you have questions, please contact the USF General Counsel or your USF Tampa Library Copyright Librarian.

Name: $\frac{\text { Fautemeh Sajadi Bami }}{\text { Class or Project: } \frac{\text { Master's Thesis }}{\text { March 1, } 2019}}$ Title of Copyrighted Work: Florida Counties Map

PURPOSE AND CHARACTER OF THE USE

\begin{tabular}{|l|l|}
\hline Likely Supports Fair Use & Likely Does Not Support Fair Use \\
\hline$\square$ Educational & $\square$ Commercial \\
$\square$ Teaching (including multiple copies for & $\square$ Entertainment \\
classroom use) & $\square$ Bad-faith behavior \\
$\square$ Research or Scholarship & $\square$ Denying credit to original author \\
$\square$ Criticism, Parody, News Reporting or & $\square$ Non-transformative or exact copy \\
Comment & $\square$ Made accessible on Web or to public \\
$\square$ Transformative Use (your new work relies on & $\square$ Profit-generating use \\
and adds new expression, meaning, or message & \\
to the original work) & \\
$\square$ Restricted Access (to students or other & \\
appropriate group) & \\
$\square$ Nonprofit & \\
\end{tabular}

Overall, the purpose and character of your use $\boxminus$ supports fair use or $\square$ does not support fair use.

NATURE OF THE COPYRIGHTED MATERIAL

\begin{tabular}{|l|l|}
\hline Likely Supports Fair Use & Likely Does Not Support Fair Use \\
\hline Factual or nonfiction & $\square$ Creative or fiction \\
曰Important to favored educational objectives & $\square$ Consumable (workbooks, tests) \\
曰 Published work & $\square$ Unpublished \\
\hline
\end{tabular}

Overall, the nature of the copyrighted material $\boxminus$ supports fair use or $\square$ does not support fair use.

AMOUNT AND SUBSTANTIALITY OF MATERIAL USED IN RELATION TO WHOLE

\begin{tabular}{|c|c|}
\hline Likely Supports Fair Use & Likely Does Not Support Fair Use \\
\hline $\begin{array}{l}\text { E Small amount (using only the amount } \\
\text { necessary to accomplish the purpose) } \\
\text { Amount is important to favored socially } \\
\text { beneficial objective (i.e. educational objectives) } \\
\text { E Lower quality from original (ex. Lower } \\
\text { resolution or bitrate photos, video, and audio) }\end{array}$ & $\begin{array}{l}\square \text { Large portion or whole work } \\
\square \text { Portion used is qualitatively substantial (i.e. it } \\
\text { is the 'heart of the work') } \\
\square \text { Similar or exact quality of original work }\end{array}$ \\
\hline
\end{tabular}

LeEtta Schmidt, Imschmidt@usf.edu and Drew Smith dsmith@usf.edu Reviewed by USF General Counsel 08/11/2015 
Overall, the amount and substantiality of material used in relation to the whole $\square$ supports fair use or $\square$ does not support fair use.

EFFECT ON THE MARKET FOR ORIGINAL

\begin{tabular}{|l|l|}
\hline Likely Supports Fair Use & Likely Does Not Support Fair Use \\
\hline G No significant effect on the market or & $\square$ Replaces sale of copyrighted work \\
potential market for the original & $\square$ Significantly impairs market or potential \\
$\begin{array}{l}\text { No similar product marketed by the copyright } \\
\text { holder }\end{array}$ & market for the work \\
$\square$ You own a lawfully acquired copy of the & $\square$ Numerous copies or repeated, long-term use \\
material & $\square$ Made accessible on Web or to public \\
$\square$ The copyright holder is unidentifiable & $\square$ Affordable and reasonably available \\
$\square$ Lack of licensing mechanism for the material & permissions or licensing \\
\hline
\end{tabular}

Overall, the effect on the market for the original $\square$ supports fair use or $\square$ does not support fair use.

CONCLUSION

The combined purpose and character of the use, nature of the copyrighted material, amount and substantiality of material used in relation to the whole and the effect on the market for the original

छlikely supports fair use or $\square$ likely does not support fair use.

Note: Should your use of copyrighted material not support fair use, you may still be able to locate and request permissions from the copyright holder. For help on this, please feel free to contact your Copyright Librarian.

This worksheet has been adapted from:

Cornell University's Checklist for Conducting A Fair use Analysis Before Using Copyrighted Materials: https://copyright.cornell.edu/policies/docs/Fair Use Checklist.pdf

Crews, Kenneth D. (2008) Fair use Checklist. Columbia University Libraries Copyright Advisory Office. http://copyright.columbia.edu/copyright/files/2009/10/fairusechecklist.pdf

Smith, Kevin; Macklin, Lisa A.; Gilliland, Anne. A Framework for Analyzing any Copyright Problem. Retrieved from: https://d396qusza40orc.cloudfront.net/cfel/Readina\%20Docs/A\%20Framework\%20for\%20Analyzinq\%20a ny\%20Copyright\%20Problem.pdf

LeEtta Schmidt, Imschmidt@usf.edu and Drew Smith dsmith@usf.edu Reviewed by USF General Counsel 08/11/2015 